\title{
The Role of Ubiquitination and SUMOylation in DNA Replication
}

\author{
Tarek Abbas ${ }^{1,2,3 *}$ \\ ${ }^{1}$ Department of Radiation Oncology, University of Virginia, Charlottesville, VA, USA. \\ ${ }^{2}$ Department of Biochemistry and Molecular Genetics, University of Virginia, Charlottesville, VA, \\ USA. \\ ${ }^{3}$ Center for Cell Signaling, University of Virginia, Charlottesville, VA, USA. \\ *Correspondence: ta8e@virginia.edu
}

https://doi.org/10.21775/cimb.040.189

\begin{abstract}
DNA replication is a tightly regulated conserved process that ensures the faithful transmission of genetic material to define heritable phenotypic traits. Perturbations in this process result in genomic instability, mutagenesis, and diseases, including malignancy. Proteins involved in the initiation, progression, and termination of DNA replication are subject to a plethora of reversible post-translational modifications (PTMs) to provide a proper temporal and spatial control of replication. Among these, modifications involving the covalent attachment of the small protein ubiquitin or the small ubiquitin-like modifier (SUMO) to replication and replicationassociated proteins are particularly important for the proper regulation of DNA replication as well as for optimal cellular responses to replication stress. In this article, we describe how the ubiq uitination and SUMOylation processes impact DNA replication in eukaryotes and highlight the consequences of deregulated signals emanating from these two versatile regulatory pathways on cellular activities.
\end{abstract}

\section{Regulation of eukaryotic DNA replication}

\section{Initiation of DNA replication}

Eukaryotic DNA replication is tightly regulated such that cells replicate their entire genome once and only once in a given cell cycle (Machida et al., 2005). For mammalian cells, this is no easy task since each proliferative somatic cell must efficiently replicate approximately 6 billion base pairs (in male cells) from roughly 250,000 replication origins scattered throughout the genome with each division cycle (Cadoret et al., 2008; SequeiraMendes et al., 2009; Karnani et al., 2010). With roughly 600 million new blood cells born in the bone marrow of an adult human (Doulatov et al., 2012), one cannot grasp the magnitude of the task the replication machinery has to accomplish. The core machinery of DNA replication is highly conserved in all living organisms, but eukaryotes diverge significantly in its regulation owing to the larger, more complex genomes (Kaguni, 2011). In bacteria (e.g. Escherichia coli), replication initiates at individual replication initiation sites or 

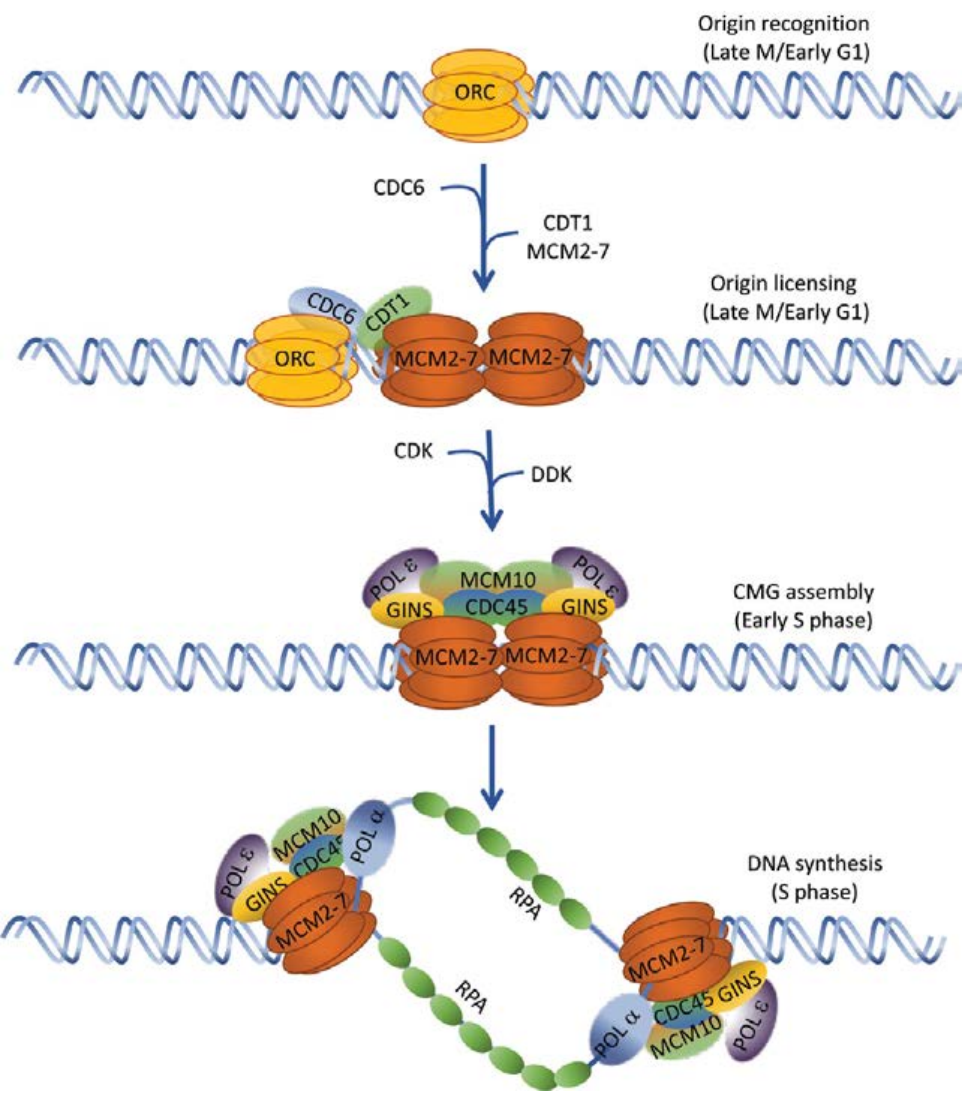

Figure 14.1 Regulation of replication initiation in eukaryotes. A model depicting the step-wise assembly of the pre-replication complex (Pre-RC) in late mitosis and during G1 phase of the cell cycle, followed by replisome assembly. The six-subunit ORC complex binds to origins of DNA replication in late $M$ and early G1. This is followed by the recruitment of the replication licensing proteins CDC6 and CDT1, and the loading the of the MCM2-7 helicase (origin licensing). At the G1/S transition, the Dbf4-dependent kinase (DDK) and CDK enzymes promote the assembly of the replicative helicase, or the CMG complex, which is marked by the recruitment of the GINS complex (Sld5, Psf1, Psf2, Psf3), along with CDC45. MCM10 aids in this process by recruiting and stabilizing DNA polymerase a (POL a). Other proteins [e.g. Treslin (SId3 in yeast), RecQL4 (Sld2 in yeast), and TopBP1] help in the replisome assembly (not shown). As DNA synthesis begins in S-phase, the unwound DNA is stabilized by the single-stranded DNA binding protein RPA, and DNA polymerases (POL $\varepsilon$ and POL $\delta$ ) initiate replication.

origin of chromosome replication (OriC) where two replication forks assemble and move in opposite direction at a rate of $1 \mathrm{~Kb} / \mathrm{sec} /$ fork to replicate the entire $4.4 \mathrm{Mb}$ circular chromosome within 30 minutes (Katayama, 2017). The AAA+ ATPase replication initiator protein DnaA, which is conserved in virtually all bacteria, recognizes and binds with high specificity to high density GATC repeat sequences (DnaA box) within these replicons, and both DNA binding and ATP hydrolysing activities of DnaA are essential for replication initiation (Hansen and Atlung, 2018). Initiation of DNA replication in eukaryotes (Fig. 14.1) is similarly dependent on the binding of a DnaA-like six-subunit origin recognition complex (ORC) to replication origins in an ATP-dependent manner (Bell and Stillman, 1992; Bell and Dutta, 2002). ORCs from various eukaryotes exhibit a wide range of sequence-recognition specificities. For example, whereas ORC from budding yeast 
specifically recognizes 11 -bp or 17 -bp conserved sequences within the $\approx 400$ autonomously replicating sequences (ARS) (Dhar et al., 2012), the fission yeast ORC recognizes AT stretches (but without sequence consensus) through the AThook motif present on the Orc4 subunit (Chuang and Kelly, 1999; Segurado et al., 2003; Dai et al., 2005; Hayashi et al., 2007). The six-subunit ORC complex from high eukaryotes binds DNA without sequences specificity (Vashee et al., 2003; Schaarschmidt et al., 2004), although replication initiates from genomic loci that are enriched for AT-rich sequences, dinucleotide repeats, asymmetrical purine-pyrimidine sequences, and matrix attachment region (MAR) sequences ( $\mathrm{Li}$ and Stillman, 2012; Kumar and Remus, 2016). Additional epigenomic features, such as the DNA topology, transcription factors and regulatory elements, local chromatin environment as well as the replication initiation proteins $\mathrm{CDT} 1$ and $\mathrm{CDC} 6$ play a role for the selectivity of ORC to stably bind replication origins (Masai et al., 2010; Li and Stillman, 2012; Kumar and Remus, 2016). Replication initiation in high eukaryotes is also dependent on histone methylation. For example, recent studies demonstrate a critical role for histone $\mathrm{H} 4$ methylation at Lys-20 (H4K20) at replication origins in the nucleation of DNA replication (Tardat et al., 2010; Beck et al., 2012a). Mono-methylation of H4K20 (H4K20me1) is catalysed by the histone methyltransferase (HMT) SET8 (also known as PR-SET7), which deposits a single methyl group on Lys-20 of nucleosomal histone H4 (Nishioka et al., 2002; Xiao et al., 2005). When tethered to specific genomic loci, catalytically active, but not inactive, SET8 recruits pre-RC proteins on chromatin and replication initiates from these sites (Tardat et al., 2010). Mono-methylated Lys-20 of H4 is subject for further methylation [di- and tri-methylation (H4K20me2 and H4K20me3, respectively)] by the SUV4-20H1/H2 HMTs (Schotta et al., 2008). The conversion of H4K20me1 to H4K20me2/3 by SUV4-20H1/H2 likely plays an important role for SET8-dependent replication initiation, as the recruitment of ORC1 as well as the ORC-associated protein (ORCA) protein (both capable of binding H4K20me in vitro) to chromatin requires SUV4-20H1/H2 (Beck et al., 2012a).

\section{Cell cycle regulation of replication initiation in eukaryotes}

Initiation of eukaryotic DNA replication is cell cycle regulated, requires the ordered assembly of several proteins at replication origins, and occurs in two distinct steps that are temporally separated within the cell cycle (Fig. 14.1). The first step involves the establishment of pre-replicative complexes (preRCs) through the sequential assembly of ORC, CDC6, and CDT1, followed by the loading of the six-subunit helicase MCM2-7 (minichromosome maintenance proteins, subunits 2-7) at origins of replication in late mitosis (M) and early G1 (first Gap) phase of the cell cycle. Once the MCM2-7 complexes are loaded onto replication origins (origin licensing), the ORC-CDC6-CDT1 pre-RC components are no longer required to initiate replication. In the second step, licensed origins are activated in $S$ phase (DNA synthesis phase) to generate active replication forks (origin firing), and this requires the conversion of the inactive double hexameric MCM2-7 helicase to an active replicative helicase, the CMG complex, which is composed of MCM2-7, its cofactor CDC45, and the GINS complex (Gambus et al., 2006; Moyer et al., 2006; Pacek et al., 2006; Ilves et al., 2010; Kang et al., 2012). This conversion process, which is highly conserved from yeast to human, requires the activity of the Dbf4-dependent kinase (DDK) and the cyclin-dependent kinase (CDK). Both kinases are activated at G1/S transition, and their concerted activities promote the recruitment of several scaffolding proteins and DNA polymerase Pole to assemble the replisome. Studies in yeast have shown that while DDK phosphorylates multiple Mcm2-7 subunits to recruit the scaffolding protein Sld3 with its partners Sld7 and Cdc45, CDK phosphorylates the two other scaffolding subunits Sld 2 and Sld3, thereby promoting their interaction with Dpb11 (TopBP1 in human) in cooperation with Pole and GINS (Gambus et al., 2006; Moyer et al., 2006; Pacek et al., 2006; Ilves et al., 2010; Muramatsu et al., 2010; Kumagai et al., 2010, 2011; Boos et al., 2011; Kang et al., 2012; Bruck and Kaplan, 2015, 2017; Fang et al., 2016). Replisome assembly also requires the action of multiple protein complexes involved in monitoring replication fork progression, in coordinating DNA synthesis with chromatin assembly, and in responding to 
genetic perturbations by generating checkpoint and damage signals (Leman and Noguchi, 2013).

\section{Progression and termination of DNA replication}

Origin firing in eukaryotes is temporally regulated with distinct early- and late-replicating genomic regions and exhibits significant flexibility that gives the cells control over situations that interfere with normal progression of replication forks (RenardGuillet et al., 2014). Activation of the CMG complex is tightly coupled to the activity of histone chaperones, nucleosome-remodelling complexes and chromatin-modifying enzymes (Groth, 2007, 2009; Jasencakova and Groth, 2010). These later factors facilitate nucleosomal disassembly ahead of the replication forks and reassembling nucleosomes with correct positioning following their passage. The DNA primase-POL $\alpha$ complex generates primers that will be extended by POLE (for continuous DNA synthesis of the leading strand) or POL $\delta$ (for the discontinuous replication of the lagging strand) (Bell and Dutta, 2002; Bell and Labib, 2016). Several other proteins are important for the maturation and ligation of the Okazaki fragments. In budding yeast, these include the flap endonuclease $\operatorname{Rad} 27$, the DNA helicase-nuclease Dna2, the Exo1 exonuclease and the DNA ligase Cdc9 (Bell and Labib, 2016). DNA topoisomerases relieve topological stresses created by the moving replication forks, and many proteins and protein complexes aid in removing other barriers to the progressing replication forks, such as tightly-bound non-histone proteins. Other proteins must be recruited to deal with difficult to replicate genomic sequences or with actively transcribing genomic templates. Progression of DNA replication is also tightly coordinated with the establishment of sister chromatid cohesion as well as with the activity of multiple proteins and protein complexes involved in the sensing and repair of DNA damage that may be encountered during DNA replication (Waters et al., 2009; Villa-Hernandez and Bermejo, 2018). Termination of DNA replication occurs at converging replication forks from neighboring origins of replication, although in some cases, termination occurs at chromosomal termination regions (TERs) defined by replication pausing elements contained within these TERs (Labib and Hodgson, 2007; Fachinetti et al., 2010). Genomic and mechanistic studies in budding yeast identified 71 such regions, and further demonstrated that these TERs can influence fork progression and merging (Fachinetti et al., 2010). Replication across these TERs, which are characterized by the accumulation of $\mathrm{X}$-shaped structures, can be facilitated by the Rrm3 DNA helicase, and the fusion of the converging forks at these sites is aided by DNA topoisomerase II (Topo II or Top2 in yeast), thus counteracting abnormal genomic transitions (Fachinetti et al., 2010). Termination of DNA replication is marked by the completion of local DNA synthesis, the decatenation of the two daughter strands by DNA topoisomerases and the final disassembly of the replisome (Dewar and Walter, 2017; Gambus, 2017).

\section{Ubiquitin-dependent regulation of DNA replication}

\section{Overview of the ubiquitin- proteasome system}

ATP-dependent and ubiquitin-mediated proteasomal degradation through the ubiquitinproteasome system (UPS) provides an efficient mean to regulate protein abundance and maintain homeostatic regulation of cellular physiology, and is involved in almost all cellular activities (Kornitzer and Ciechanover, 2000; Amir et al., 2001; Ciechanover and Schwartz, 2002; Glickman and Ciechanover, 2002; Hershko, 2005; Schwartz and Ciechanover, 2009). The process ensures the timely down-regulation of cellular proteins via the $26 \mathrm{~S}$ proteasome, where roughly $80 \%$ of all intracellular proteins are digested into small peptides (Skaar $e t$ al., 2014). Proteasomal degradation is preceded by the covalent attachment of multiple copies of the highly conserved 76 amino-acid ubiquitin protein [linked together through Lys-48 (Lys-48 linkage) or Lys-11 (Lys-11 linkage)] to substrate proteins (Fig. 14.2). This occurs in a series of enzymatic reactions involving the activity of an E1 ubiquitinactivating enzyme, the transfer of the activated ubiquitin to an E2 ubiquitin-conjugating enzyme (UBC), and the selective transfer of ubiquitin to the substrate through the activity of an E3 ubiquitin ligase (Glickman and Ciechanover, 2002; Groll and Huber, 2003; Kornitzer and Ciechanover, 2000; Teixeira and Reed, 2013). Whereas Lys-48 and Lys-11- polyubiquitination signal proteolytic 


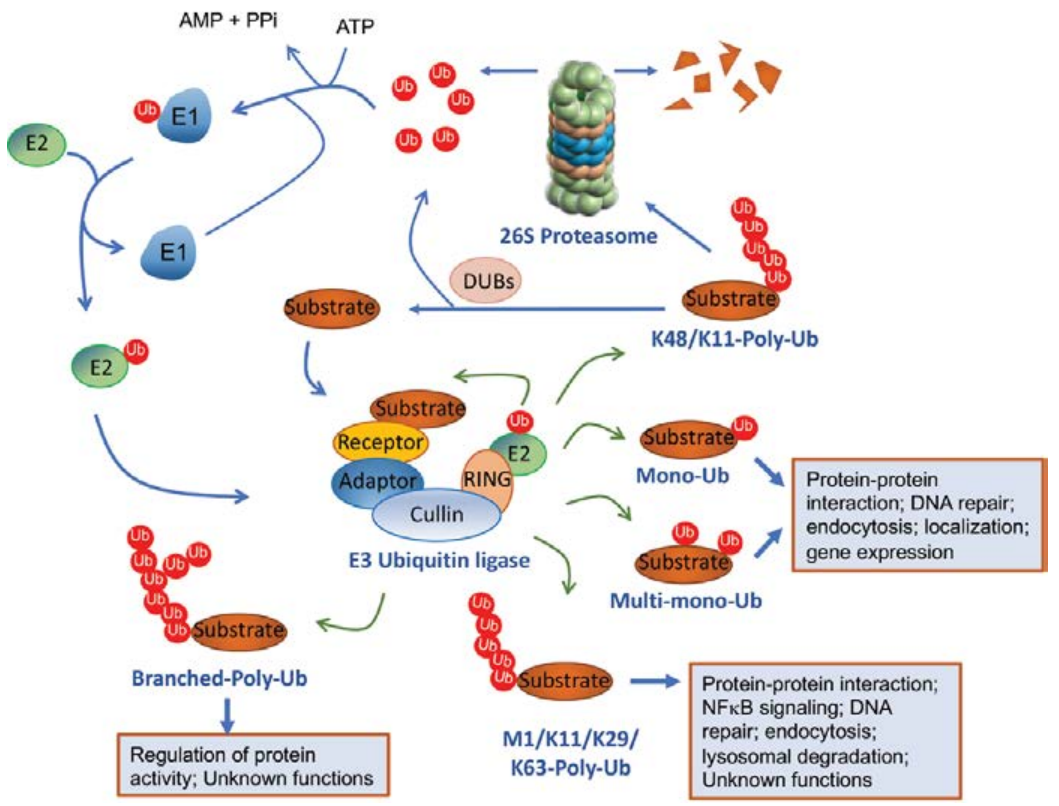

Figure 14.2 Regulation of protein ubiquitination. Protein ubiquitination involves the sequential activity of an E1 ubiquitin activating enzyme, an E2 ubiquitin conjugating enzyme and an E3 ubiquitin ligase (a cullin-based E3 ubiquitin ligase is shown as an example). The E3 ligase transfers the ubiquitin moiety (Ub) to the substrate through interaction with the E2-charged ubiquitin, forming a covalent isopeptide bond between the C-terminus of ubiquitin and a specific Lys residue on the substrate. Polyubiquitin chains (poly-Ub) can be formed by covalently conjugating the C-terminus of a ubiquitin moiety to one of seven Lys residues (e.g. Lys-48) or to the fist Met residue (M1) on another ubiquitin moiety. Polyubiquitination through Lys-48 (K48), and Lys-11 (K11) linkages directs the substrate to the 26S proteasome, where the substrate is proteolytically degraded into small peptides, with the ubiquitin moieties released and recycled. Other homotypic poly-ubiquitin chains [e.g. M1, Lys-63 (K63)], or the attachment of single ubiquitin moieties to individual (mono-ubiquitination) or multiple (multi-ubiquitination) Lys residues do not signal protein degradation and serves other distinct biological functions. A set of deubiquitinating enzymes (DUBs), which are highly specific cysteine proteases, can cleave the isopeptide bonds between the ubiquitin and $\varepsilon$-amino group of the substrate Lys or the Lys of the other ubiquitin moiety in a polyubiquitin chain. DUBs can also cleave the peptide bond between ubiquitin and the $\mathrm{N}$-terminal methionine of another ubiquitin moiety.

degradation, other homotypic poly-ubiquitin chains involving ubiquitin conjugation through Lys-63 or Met-1, or the attachment of single ubiquitin moieties to individual (mono-ubiquitination) or multiple (multi-ubiquitination) Lys residues do not signal protein degradation, but play a role in various cellular process (Fig. 14.2). These include activities that impact protein-protein interaction, transcription factor activation, protein synthesis, and cellular response to DNA damage (Wang et al., 2001; Tokunaga et al., 2009; Yang et al., 2010; Behrends and Harper, 2011; Dantuma and Pfeiffer, 2016; Schwertman et al., 2016).

E3 ubiquitin ligases are critical for conferring specificity for the substrates to be ubiquitinated and, in some cases, for dictating the nature of substrate ubiquitination (Zheng and Shabek, 2017). Cullin-RING (Really Interesting New Gene) E3 ubiquitin Ligases (CRLs) represent the largest family of E3 ubiquitin ligases in mammals, promoting the polyubiquitin-mediated degradation of approximately $20 \%$ of total cellular proteins via the proteasome (Hotton and Callis, 2008; Deshaies and Joazeiro, 2009; Soucy et al., 2009; Duda et al., 2011; Hua and Vierstra, 2011; Lipkowitz and Weissman, 2011; Sarikas et al., 2011; Lydeard et al., 2013; Chen et al., 2015). Other E3 ubiquitin ligases including the HECT (Homologous to the E6-AP Carboxyl Terminus) domain containing E3 ubiquitin ligases are described in more details in 
recent excellent reviews (Li et al., 2008; Deshaies and Joazeiro, 2009; Skaar et al., 2014; Zheng and Shabek, 2017). CRLs are involved in many cellular processes, including DNA replication, cell cycle progression and cellular proliferation (Petroski and Deshaies, 2005; Bosu and Kipreos, 2008; Hotton and Callis, 2008). CRL family members include eight cullin proteins (cullin 1-3, 4A, 4B, 5, 7 and cullin 9) and a cullin-like protein ANAPC2 or APC2. The multi-subunit CRL1 E3 complex, better known as the SCF ligase (KIP1-Cullin1-FBox protein), is the prototype of this family of E3 ligases and is best known for its role in controlling cell cycle progression, proliferation, and differentiation (Nakayama and Nakayama, 2005; Maser et al., 2007; Welcker and Clurman, 2008; Huang et al., 2010; Duan et al., 2012; Lee and Diehl, 2014). The SCF ubiquitin ligase is built around the cullin 1 scaffold subunit, which binds the SKP1
(S-phase kinase-associated protein 1) adaptor protein through its N-terminal domain (Fig. 14.3). The SKP1 subunit bridges one of several substrate receptors with their cognate substrates to the cullin 1 subunit (Wang et al., 2014). The cullin 1 C-terminal domain, on the other hand, is essential for substrate polyubiquitination through its interaction with a small RING domain protein (RBX1 or RBX2), which is essential for the recruitment of the E2 UBCs. The substrate specificity of the SCF ligase complex is dictated by a family of substrate receptors, which are collectively called F-box proteins owing to their interaction with the SPK1 protein through conserved F-box motif (Skaar et al., 2014; Heo et al., 2016). Mammalian cells express at least 69 F-box proteins, and thus assemble a large number of distinct SCF ligases. Each F-box protein is capable of recognizing a subset of ubiquitination substrates, commonly through interaction with

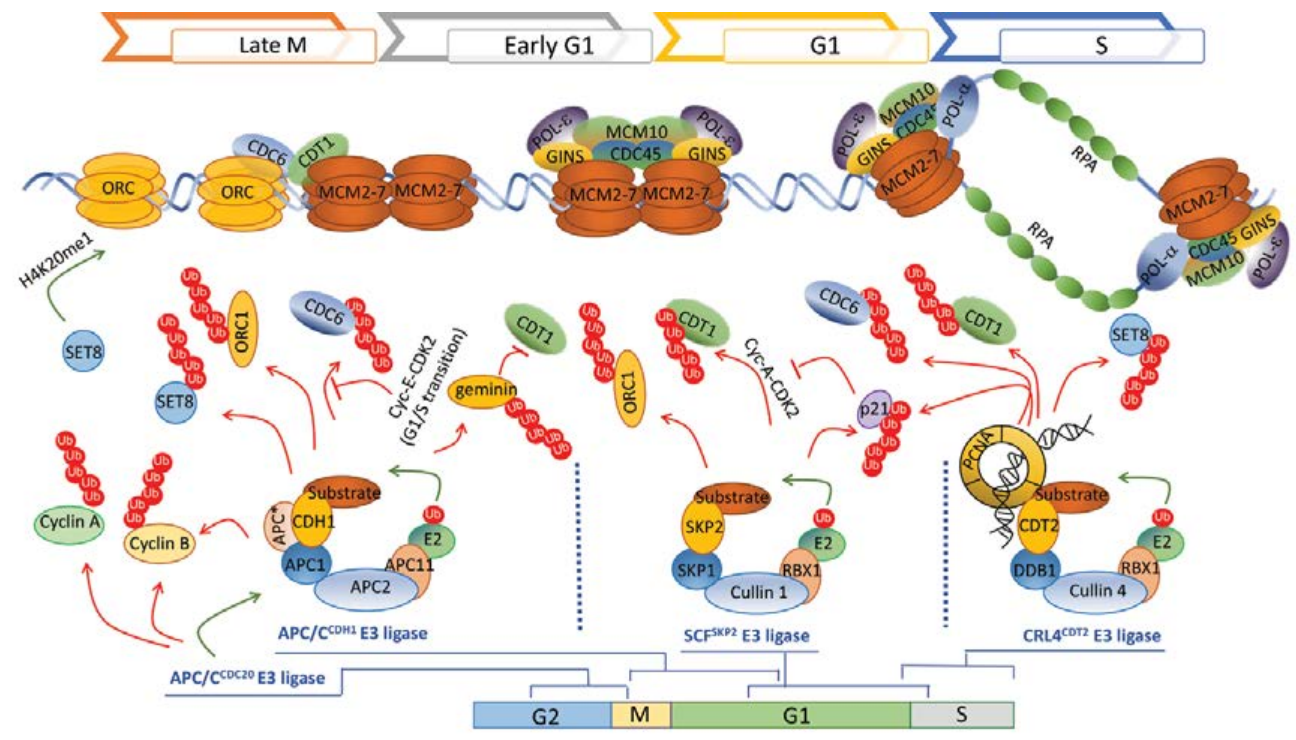

Figure 14.3 Regulation and restraint of origin licensing via the UPS. A schematic illustrating the various steps involved in origin licensing through the cell early part of the cell cycle and their regulation via the UPS. Three E3 ubiquitin ligases [APC/C ${ }^{\mathrm{CDH} 1}$ (left) SCFSKP2 (centre), and CRL4 ${ }^{\mathrm{CDT} 2}$ (right)] ensure the ordered but restricted assembly of the various pre-RC components in late $M$ and early $\mathrm{G} 1$ phase of the cell cycle. APC/C ${ }^{\mathrm{CDC} 20}$ (not represented schematically) helps promote mitotic cyclin degradation and helps assembly of the AP ligase APC/ $\mathrm{C}^{\mathrm{CDH}}$ 1. These $\mathrm{E} 3$ ligases are activated at distinct phases of the cell cycle (represented below). Distinct substrate receptors, $\mathrm{CDC} 20$ or $\mathrm{CDH} 1$, an F-box protein (SKP2), or a DCAF (CDT2) is critical for bridging the substrates for polyubiquitination by their cognate E3 ligases (APC/C, SCF, and CRL4 ligase, respectively). The CRL4CDT2 ligase recognizes its substrates only when they interact with chromatin-bound PCNA, and thus, only targets chromatin-bound proteins for degradation. Other substrates are targeted for ubiquitination only in their soluble form (see text for details). M: mitosis. G1/S/G2: First gap, DNA synthesis and second phases of the cell cycle, respectively. $\mathrm{APC}^{\star}$ multiple subunits that together function as adaptor proteins 
phosphorylated residues within small consensus 'degron' motifs in these substrates (Kipreos and Pagano, 2000; Cardozo and Pagano, 2004; Skaar et al., 2013; Wang et al., 2014; Heo et al., 2016).

Ubiquitination is reversible and protein abundance is controlled by a set of deubiquitinases or DUBs (Fig. 14.2). DUBs play pivotal roles in the regulation of protein turnover, protein or enzymatic activation, protein-protein interaction, protein recycling, and cellular localization (Mukhopadhyay and Dasso, 2007; Komander et al., 2009; Reyes-Turcu et al., 2009; Hickey et al., 2012), and are increasingly recognized as attractive therapeutic targets for cancer therapy (Hoeller and Dikic, 2009; Crosas, 2014; D’Arcy et al., 2015; Pfoh et al., 2015; Lei et al., 2017; Harrigan et al., 2018). Biochemically, DUBs hydrolyse the isopeptide bonds between the $\varepsilon$ amino group of Lys side chains of the target substrate and the C-terminal group of ubiquitin, or the peptide bond between the $\alpha$ amino group of the target protein and the C-terminus of ubiquitin (Wilkinson, 1997).

\section{Regulation of cell cycle control of replication via the UPS}

The $\mathrm{SCF}^{\mathrm{SKP} 2}$ E3 ubiquitin ligase (Fig. 14.3), composed of the core SCF complex and the substrate receptor SKP2 (S-phase kinase-associated protein 2 ), is one of the best characterized SCF ligases and best known for its role in promoting cell cycle progression through the activation of CDKs (Nakayama and Nakayama, 2005; Skaar et al., 2013). CDK activity controls replication initiation, and the $\mathrm{SCF}^{\mathrm{SKP} 2}$ ligase is critical for increasing $\mathrm{CDK}$ activity in $\mathrm{G} 1$ and in early $\mathrm{S}$ phase, by promoting the ubiquitination CDK inhibitors $\mathrm{p} 21^{\mathrm{CIP} 1}$, p2 $7^{\mathrm{KIP} 1}$, and $\mathrm{p} 57^{\mathrm{KIP} 2}$ (Nakayama and Nakayama, 2005; Skaar et al., 2013). SCF ${ }^{\text {SKP2 }}$ also promotes progression through G2 phase, primarily through its ability to promote the ubiquitin-dependent proteolysis of cyclin A. The degradation of cyclin A in late $S$-phase ensures the availability of sufficient CDK1 molecules to assemble cyclin B-CDK1 complexes essential for progression through G2. Progression through $S$ phase also requires the availability of sufficient CDK2 molecules for assembly with cyclin $\mathrm{A}$, and this is mediated, at least in part, through the activity of the $\mathrm{SCF}^{\mathrm{FBXW7}}$ ligase, which utilizes FBXW7 as a substrate receptor to degrade CDK2-phosphorylated cyclin E following entry into S phase (Clurman et al., 1996; Koepp et al., 2001).

CDK activity must be kept low during mitosis and in early G1, and this is facilitated by the multisubunit APC/C (anaphase promoting complex/ cyclosome) ubiquitin ligase (Fig. 14.3), which promotes the ubiquitination and degradation of cyclin A and cyclin B (den Elzen and Pines, 2001). $\mathrm{APC} / \mathrm{C}$ complex is the largest $\mathrm{E} 3$ ubiquitin ligase in mammals that is built around the APC2 cullinlike scaffold and utilizes the CDH1 (Hct1 in yeast) or CDC20 substrate receptors for recognizing and promoting the polyubiquitination (both Lys-48and Lys-11-linked ubiquitin conjugation) of key drivers of the cell cycle (Visintin et al., 1997; Zachariae and Nasmyth, 1999; Pines, 2006; van Leuken et al., 2008). The specificity of the APC/C ligases is based on the substrate receptors $\mathrm{CDH} 1 / \mathrm{CDC} 20$ ability to recognize degron motifs (destruction D-boxes and KEN-boxes) within the targeted substrates (Pfleger and Kirschner, 2000; Pfleger et al., 2001). The $\mathrm{APC} / \mathrm{C}^{\mathrm{CDC} 20}$ is activated in $\mathrm{G} 2$ and in early mitosis in a cyclin $\mathrm{B}-\mathrm{CDK} 1$-dependent manner, and this is critical for the initial degradation of mitotic cyclins (cyclin A in prometaphase and cyclin B in metaphase) (Rahal and Amon, 2008). The $S C^{\beta{ }^{\beta R C P 1}}$ ligase utilizing the substrate receptor $\beta$-transducin-repeat-containing protein 1 ( $\beta$ TRCP1) aids in activating APC/ $\mathrm{C}^{\mathrm{CDC} 20}$ both by stimulating $\mathrm{CDK} 1$ activity through enhancing the ubiquitination and degradation of the CDK1 tyrosine kinase inhibitor Wee1, and by relieving inhibition of the $\mathrm{APC} / \mathrm{C}^{\mathrm{CDC} 20}$ via promoting the degradation of the F-box protein and early mitotic inhibitor 1 (EMI1), which is an endogenous inhibitor of APC/C (Guardavaccaro et al., 2003; Watanabe et al., 2004). Cyclin B-CDK1 subsequently phosphorylates the APC 3 and APC1 subunits of the APC/C ligase, thereby facilitating the docking of $\mathrm{CDC} 20$ onto the APC/C ligase and the assembly of the active ligase complex (Fujimitsu et al., 2016). Cyclin B-CDK1 additionally phosphorylates $\mathrm{CDH1}$, resulting in conformational changes in $\mathrm{CDH} 1$ that preclude the assembly of an active $\mathrm{APC} / \mathrm{C}^{\mathrm{CDH} 1}$ ligase.

In late mitosis and through G1, CDC20 is exchanged for $\mathrm{CDH} 1 /$ Hct1 following the dephosphorylation and activation of CDH1 by the CDC14A phosphatase (Cdc14 in yeast), and the newly assembled $\mathrm{APC} / \mathrm{C}^{\mathrm{CDH} 1 / \mathrm{Hctl}}$ ligase complex 
maintains low cyclin B levels (Jaspersen et al., 1999; Donzelli et al., 2002; Sullivan and Morgan, 2007; Robbins and Cross, 2010). APC/ $\mathrm{C}^{\mathrm{CDH1} / \mathrm{Hctl}}$ activation is facilitated by $\mathrm{APC} / \mathrm{C}^{\mathrm{CDC} 20}$, which mediates the release of the $\mathrm{CDC} 14 \mathrm{~A}$ from centrosomes (and yeast $\mathrm{Cdc} 14$ phosphatase from the nucleolus) through an unknown mechanism (Shirayama et al., 1999; Bembenek and Yu, 2001; Kaiser et al., 2002; Mocciaro et al., 2010; Chen et al., 2016). $\mathrm{APC} / \mathrm{C}^{\mathrm{CDH}}$ ligase activity is critical for inactivating mitotic $\mathrm{CDK}$ and for exit from mitosis. This is accomplished via the APC/C $\mathrm{CDH1}^{\mathrm{Hctl}}$-dependent polyubiquitination and degradation of not only mitotic cyclins, but also of CDC20, thereby stabilizing the $\mathrm{APC} / \mathrm{C}^{\mathrm{CDC} 20}$ ligase ubiquitination substrate and the CDK inhibitor p21 (or its homologue in yeast, Sic1) (Shirayama et al., 1999; Amador et al., 2007). APC/ $\mathrm{C}^{\mathrm{CDH} 1}$ maintains low $\mathrm{CDK}$ activity through early G1 by promoting the degradation of the SKP2 subunit of the SCF ${ }^{\text {SKP2 }}$ ligase (Bashir et al., 2004; Wei et al., 2004). This prevents the premature degradation of the CDK inhibitors p21 and p27, which can bind to and inhibit CDK2 in G1 (Abbas and Dutta, 2009). At the G1/S transition, the $\mathrm{APC} / \mathrm{C}^{\mathrm{CDH} 1 / \mathrm{Hctl}}$ ligase is inactivated through the phosphorylation of the $\mathrm{CDH} 1 / \mathrm{Hct} 1$ subunit by cyclin E-CDK2 (Cappell et al., 2016). Further inhibition of CDH1 (and CDC20) is mediated by EMI1, and this has been proposed to mark a 'point of no return' for entry into S-phase (Reimann et al., 2001; Cappell et al., 2016). Stabilization of mitotic cyclins is essential for the completion of DNA synthsis and for progression throguh G2 (Di Fiore and Pines, 2007).

\section{Ubiquitin-dependent restraint of origin licensing}

One of the most important features of regulating DNA replication in eukaryotes is the uncoupling of origin licensing, which takes place in late $\mathrm{M}$ and early G1, from origin firing in S-phase (Fig. 14.3). This ensures that replication initiates from individual origins of replication during $S$ phase and is prevented from firing again until nuclear division is completed. The fluctuating CDK activity during the cell cycle, which is largely dependent on the ubiquitin-dependent proteolysis described above, is essential for this uncoupling process. The rising CDK activity in $S$ phase is incompatible for origin licensing as many of the origin licensing proteins are phosphorylation substrates for CDK. CDK-dependent phosphorylation of certain replication licensing proteins suppresses origin licensing, either because this triggers their ubiquitination and proteolytic degradation or results in their exclusion from the nucleoplasm (Blow and Dutta, 2005; Abbas and Dutta, 2017). For example, CDK-phosphorylated human ORC1 protein, the largest subunit of the ORC complex, undergoes ubiquitin-dependent proteolysis specifically in $S$ phase cells, and this is mediated by the SCF ${ }^{\text {SKP2 }}$ ubiquitin ligase (Méndez et al., 2002; Tatsumi et al., 2003). Unlike human ORC1, ORC1 from Drosophila undergoes ubiquitin-dependent proteolysis via the $\mathrm{APC} / \mathrm{C}^{\mathrm{FZr} / \mathrm{CDH} 1} \mathrm{E} 3$ ligase as soon as cells exit mitosis and requires a domain in the $\mathrm{N}$-terminus of Drosophila ORC1 that is non-conserved in human ORC1 (Araki et al., 2003, 2005; NarbonneReveau et al., 2008).

The replication licensing protein CDC6 is also targeted for proteolysis through the UPS, and this ensures that replication occurs only once during each division cycle. Although yeast $\mathrm{Cdc} 6$, a factor essential for loading $\mathrm{Mcm} 2-7$ onto replication origins is ubiquitinated through the $\mathrm{SCF}^{\mathrm{Cdc} 4} \mathrm{E} 3$ ubiquitin ligase, mammalian CDC6 was previously shown to be shuttled outside the nucleus through the rising CDK activity at the G1/S transition, and this was sufficient to prevent origin relicensing (Aparicio et al., 1997; Tanaka et al., 1997; Saha et al., 1998; Fujita et al., 1999; Jiang et al., 1999; Petersen et al., 1999; Alexandrow and Hamlin, 2004). However, recent evidence suggests that mammalian CDC6 also undergoes ubiquitin-dependent proteolysis. Three E3 ubiquitin ligases are implicated in restricting the expression of mammalian CDC6 to late mitosis and early G1. In G1 cells, and in cells exiting the cell cycle into quiescence, mammalian CDC6 is ubiquitinated and degraded via the APC/ $\mathrm{C}^{\mathrm{CDH1}}$ ligase, and this is dependent on an interaction between the substrate receptor $\mathrm{CDH} 1$ and CDC6 (Petersen et al., 2000). This ubiquitin-dependent degradation of CDC6 ensures that origin licensing is completed before cells transverse through G1 phase and is dependent on the D-box and KENbox motifs of CDC6, since a combination of point mutations of these motifs stabilizes CDC6 both in G1 and in quiescent cells. In cells entering the cell cycle from quiescence, and as cyclin E-CDK2 activity builds up, CDC6 is phosphorylated by cyclin 
E-CDK2, and this prevents CDC6 recognition by $\mathrm{CDH} 1$, and promotes origin licensing before entry into $S$ phase (Mailand and Diffley, 2005). In S and in G2 phases of the cell cycle, mammalian CDC6 is ubiquitinated and degraded via the activity of the $\mathrm{CRL} 4^{\mathrm{CDT} 2}$ and the $\mathrm{SCF}^{\mathrm{Cyclin} F}$, respectively, and both of these activities are essential for preventing origin relicensing and rereplication (Clijsters and Wolthuis, 2014; Walter et al., 2016).

\section{The role of CRL4 $4^{\mathrm{CDT} 2}$ and the APC/C ubiquitin ligases in restraining origin licensing}

In addition to CDC6, CDT1 is another major ubiquitination and degradation substrate for the CRL4 ${ }^{\text {CDT2 }}$ ubiquitin ligase (Fig. 14.3). The multisubunit CRL4 ligase complexes share common features with SCF ligases but utilize a different set of substrate adaptors collectively known as DCAFs (DDB1 and Cullin 4 associated factors) (Angers et al., 2006; Higa and Zhang, 2007). DCAFs include at least 49 family members of WD motif-rich proteins that, similar to the F-box protein substrate receptors of the CRL1 ligases, recognize and recruit substrates for polyubiquitination by the CRL4 ligase (Angers et al., 2006; He et al., 2006; Higa et al., 2006; Jin et al., 2006). The core CRL4 complex is comprised of one of two paralogues, cullin $4 \mathrm{~A}$ or cullin 4B, that binds DDB1 (DNA damage-specific protein-1) through its $\mathrm{N}$-terminus (Fig. 14.3). DDB1 is an adaptor protein that is analogous to the SKP1 subunit in the SCF ligases, and functions to bridges one of the DCAFs to the cullin subunit. The C-terminus of the cullin 4 subunit binds to RBX1 or RBX2, which are required for the recruitment of E2 UBCs, necessary for polyubiquitination. The DCAF CDT2 assembles with CRL4 to form a rather unique $\mathrm{E} 3$ ubiquitin ligase that appears to recognize its substrates when they interact with the DNA polymerase $\delta$ processivity factor proliferating cell nuclear antigen (PCNA) through a specialized PCNA-interacting protein motif or PIP-box, and only when PCNA is loaded onto chromatin (Arias and Walter, 2006; Senga et al., 2006). This likely restricts the CRL4 ${ }^{\mathrm{CDT} 2}$ activity to $\mathrm{S}$ and early G2 phases of the cell cycle as well as during the repair of certain DNA lesions that requires PCNA (e.g. nucleotide excision repair) (Higa et al., 2003; Abbas and Dutta, 2011; Havens and Walter, 2011; Abbas et al., 2013). The PIP-box contained within
CRL4 ${ }^{\mathrm{CDT} 2}$ substrates, commonly referred to as the 'PIP degron', is a variant of the PIP-box motif that is commonly used by many proteins to interact with PCNA, and contains, in addition to the canonical sequence [Q-X-X-(I/L/M)-X-X-(F/Y)-(F/Y)], conserved $\mathrm{Thr}$ and Asp acid residues at positions 5 and 6 respectively, as well as a basic amino acid residue c-terminal of the PIP-box (at position +4 ), as well as a second basic amino acid at position +3 or +5 (or both) (Havens and Walter, 2009, 2011; Abbas et al., 2010; Michishita et al., 2011).

The ability of CRL4 ${ }^{\mathrm{CDT} 2}$ to prevent origin relicensing and rereplication was initially attributed to its ability to specifically target CDT 1 for proteolysis during $S$ phase (Arias and Walter, 2006; Jin et al., 2006; Nishitani et al., 2006; Senga et al., 2006). In fact, in various eukaryotes, with the exception of budding yeast where Cdt 1 is exported to the cytoplasm along with the Mcm2-7 complex (Devault et al., 2002; Tanaka and Diffley, 2002), deficiency in cullin 4, DDB1 or in CDT2 induces rereplication and genomic instability reminiscent of that seen following CDT1 overexpression (Vaziri et al., 2003; Zhong et al., 2003; Jin et al., 2006; Lovejoy et al., 2006; Sansam et al., 2006; Tatsumi et al., 2006; Kim et al., 2008). Rereplication induced by CRL4 ${ }^{\mathrm{CDT} 2}$ inactivation results in the accumulation of DSBs, presumably due to the accumulation of replication intermediates and replication fork stalling/collapse, and activates DNA damage checkpoints, both of which can be partially suppressed through the co-depletion of CDT1 (Zhu et al., 2004; Lovejoy et al., 2006; Zhu and Dutta, 2006). We now know that $\mathrm{CRL} 4{ }^{\mathrm{CDT} 2}$ prevents rereplication through promoting the polyubiquitination and degradation of multiple proteins involved in origin licensing during S and G2 (Fig. 14.3). These include not only CDC6 and CDT1, but also SET8 and p21, both of which bind PCNA through PIP degrons (Abbas et al., 2010; Abbas et al., 2008; Centore et al., 2010; Clijsters and Wolthuis, 2014; Jørgensen et al., 2011; Kim et al., 2008; Nishitani et al., 2008; Oda et al., 2010; Tardat et al., 2010). The Drosophila melanogaster E2f1 transcription factor is another ubiquitination substrate for CRL4C ${ }^{\text {DT2 }}$ whose degradation in S-phase is critical for rereplication suppression and is dependent on the interaction between E2f1 and PCNA through a PIP degron that is absent in the human protein (Shibutani et al., 2008). 
The PCNA-dependent and CRL4 ${ }^{\mathrm{CDT} 2}$ catalysed polyubiquitination and degradation of chromatinbound $\mathrm{p} 21$ in $\mathrm{S}$ phase is important for sustaining elevated CDK2 activity essential for $\mathrm{S}$ phase progression and for freeing PCNA from inhibitory $\mathrm{p} 21$ (Abbas and Dutta, 2009). Increased stability of p21 following CRL4 ${ }^{\mathrm{CDT} 2}$ inhibition contributes to the rereplication phenotype observed in these cells, presumably because of inhibition of CDK activity, a condition compatible for origin licensing, but not likely to be sufficient to do so in the absence of stabilized CDT1 and SET8. This is evident by the fact that the expression of PCNA binding-deficient mutant of p21 (p21 $\left.1^{\Delta \mathrm{PIP}}\right)$, which is resistant to $\mathrm{CRL} 4{ }^{\mathrm{CDT} 2}$-mediated polyubiquitination and degradation induces robust senescence but is only associated with minor rereplication (Kim et al., 2008; Benamar et al., 2016). This is contrary to the role of stabilized SET8 in rereplication induction in cells with inactivated CRL4 ${ }^{\mathrm{CDT} 2}$, which is both necessary and sufficient to induce rereplication (Abbas et al., 2010; Tardat et al., 2010; Benamar et al., 2016). It is important to note that both $\mathrm{p} 21$ and CDT1 are also necessary for rereplication induction in cells expressing CRL4 ${ }^{\mathrm{CDT} 2}$-resistant mutant SET8 protein (SET8 ${ }^{\triangle \mathrm{PIP}}$ ) (unpublished observations). Although the role of SET8 in promoting rereplication when stabilized in $S$ phase is not entirely clear, it is likely to be dependent on its ability to monomethylate $\mathrm{H} 4 \mathrm{~K} 20$ and the subsequent conversion of this histone mark to H4K20me2/3 at replication origins (Abbas et al., 2010; Tardat et al., 2010 Beck et al., 2012a;).

Unlike chromatin-bound CDT1, p21 and SET8, soluble forms of these proteins are targeted for ubiquitination and proteolysis both in late G1 and/ or $\mathrm{S}$ phase by other ubiquitin ligases, most notably, the $\mathrm{SCF}^{\mathrm{SKP} 2}$ ligase (Fig. 14.3). This E3 ligase targets CDT1 for ubiquitination and degradation following its phosphorylation at Thr-29 by cyclin A-CDK2 in late G1 and in S phase (Li et al., 2003; Liu et al., 2004; Takeda et al., 2005). Similarly, p21 is phosphorylated at Ser-130 by CDK2 and this promotes the degradation of soluble p21 at the G1/S transition and in S phase (Bornstein et al., 2003). Soluble SET8 was also suggested to be targeted for ubiquitination via the $\mathrm{SCF}^{\mathrm{SKP} 2}$ ligase in $\mathrm{S}$ phase, although it is not clear whether this requires SET8 phosphorylation (Yin et al., 2008; Oda et al., 2010). However, depletion or deletion of SKP2, unlike CRL4 ${ }^{\mathrm{CDT} 2}$ inactivation, does not induce rereplication, suggesting that even in the presence of increased soluble fractions of these proteins, the $\mathrm{CRL} 4{ }^{\mathrm{CDT} 2}$ is sufficient to prevent origin licensing by efficiently removing the chromatin-bound forms of these proteins.

Although CDT1,p21 and SET8 are largely undetectable in late G1 and throughout most of S-phase, they reappear in late $S$ phase and in G2 (Abbas et al., 2010). In the case of CDT1, this accumulation is critical for progression through G2, but this is not likely to be dependent on CDT1 ability to bind chromatin. This conclusion stems from the observation that CDT1 is phosphorylated by CDK1 in late $S$ and early G2, and this prevents CDT1 from binding to chromatin, and that abolishing CDK1dependent phosphorylation of CDT1 inhibits cell cycle progression (Rizzardi et al., 2015). CDT1 is additionally phosphorylated by the stress-activated mitogen-activated protein kinases (MAPK) p38 and JNK and this too, precludes recognition by CRL4 ${ }^{\mathrm{CDT} 2}$ (Chandrasekaran et al., 2011). A recent study suggested that CDT 1 is also ubiquitinated and degraded in G2 cells via the $\mathrm{SCF}^{\mathrm{FBXO} 31}$ ubiquitin ligase, and that inactivation of this pathway results in minor rereplication (Johansson et al., 2014). It is unclear from this study however, how the stabilized $\mathrm{CDT} 1$ in $\mathrm{G} 2$ cells with inactivated $\mathrm{SCF}^{\mathrm{FBXO} 31}$ gains access to chromatin in the presence of elevated CDK1 activity. The reaccumulation of SET8 in G2, similar to CDT1, is critical for cell cycle progression, and this is thought to be mediated through its ability to promote histone $\mathrm{H} 4$ methylation needed for chromatin condensation prior to entry into mitosis (Beck et al., 2012b; Jørgensen et al., 2013). Following the accumulation of methylated H4K20, and from prophase to early anaphase, cyclin B/ CDK1 phosphorylates SET8 on Ser-29, and this removes SET8 from chromatin, without inhibiting its methyltransferase activity (Wu et al., 2010). The dephosphorylation of SET8 in late M-phase by the CDC14 phosphatase primes the SET8 protein for proteolytic degradation via the $\mathrm{APC} / \mathrm{C}^{\mathrm{CDH} 1}$ ligase (Wu et al., 2010). The importance of $\mathrm{p} 21$ reaccumulation in G2 on the other hand, is not clear, but may be important to restrict cyclin A-CDK2 activity.

In addition to the mechanisms by which CDT1 is targeted for proteolysis in late G1 and in $S$ phase, metazoans evolved another mechanism 
to suppress CDT1 activity through the expression of a small protein inhibitor of CDT1 called geminin (Wohlschlegel et al., 2000; Tada et al., 2001). Geminin is under the transcriptional control of E2F1, which transactivates dozen other genes essential for S-phase progression, including cyclin E (Wong et al., 2011). Geminin, however, undergoes ubiquitin-dependent degradation in late mitosis and early $\mathrm{G} 1$ via the $\mathrm{APC} / \mathrm{C}^{\mathrm{CDH} 1} \mathrm{E} 3$ ligase activity (McGarry and Kirschner, 1998). In late G1 and early S-phase, geminin is phosphorylated by cyclin E-CDK2, and this prevents its recognition by $\mathrm{CDH} 1$, stabilizing the protein, which directly binds CDT1 and sterically hinders its ability to recruit MCM2-7 complexes to replication origins (Tada, 2007; Caillat and Perrakis, 2012). At the same time, cyclin E-CDK2 phosphorylates $\mathrm{CDH} 1$, thereby inactivating $\mathrm{APC} / \mathrm{C}^{\mathrm{CDH} 1}$ (Cappell et al., 2016). In addition, residual $\mathrm{CDH} 1$ is inhibited by EMI1, marking a 'no return' decision to enter S-phase (Cappell et al., 2016). EMI1 also binds CDC20 and inhibits the APC/ $\mathrm{C}^{\mathrm{CDC} 20}$ ligase in S-phase, thereby stabilizing mitotic cyclins $\mathrm{A}$ and $\mathrm{B}$, which are essential for the completion of DNA synthesis and G2 progression (Reimann et al., 2001; Di Fiore and Pines, 2007; Cappell et al., 2016). As mentioned above, in $S$ phase, the $\mathrm{SCF}^{\mathrm{SKP} 2}$ ligase cooperates with $\mathrm{CRL} 4^{\mathrm{CDT} 2}$ to promote the degradation of soluble and chromatin-bound CDT1, respectively. The former pathway is aided by cyclin A-CDK2, which phosphorylates CDT1 at Thr-29, and requires EMI1 for suppressing $\mathrm{APC} / \mathrm{C}^{\mathrm{CDC} 20}$, which would otherwise ubiquitylate and degrade not only cyclin A, but also geminin. Whereas suppressing geminin initiates rereplication in certain cell types, it is insufficient to do so in some other cancer cell types or in non-malignant cells (Machida and Dutta, 2007; Zhu and Depamphilis, 2009; Benamar et al., 2016). Activation of $S$ phase APC/C ligase on the other hand (e.g. by depleting EMI1), is sufficient to initiate rereplication in the majority of mammalian cells examined (Machida and Dutta, 2007; Benamar et al., 2016). Together, these findings highlight the importance of $\mathrm{CRL} 4^{\mathrm{CDT} 2}$ and EMI1 for restraining origin licensing in $S$ phase by preventing the accumulation of chromatin-bound and active CDT1, as well as other replication licensing proteins.

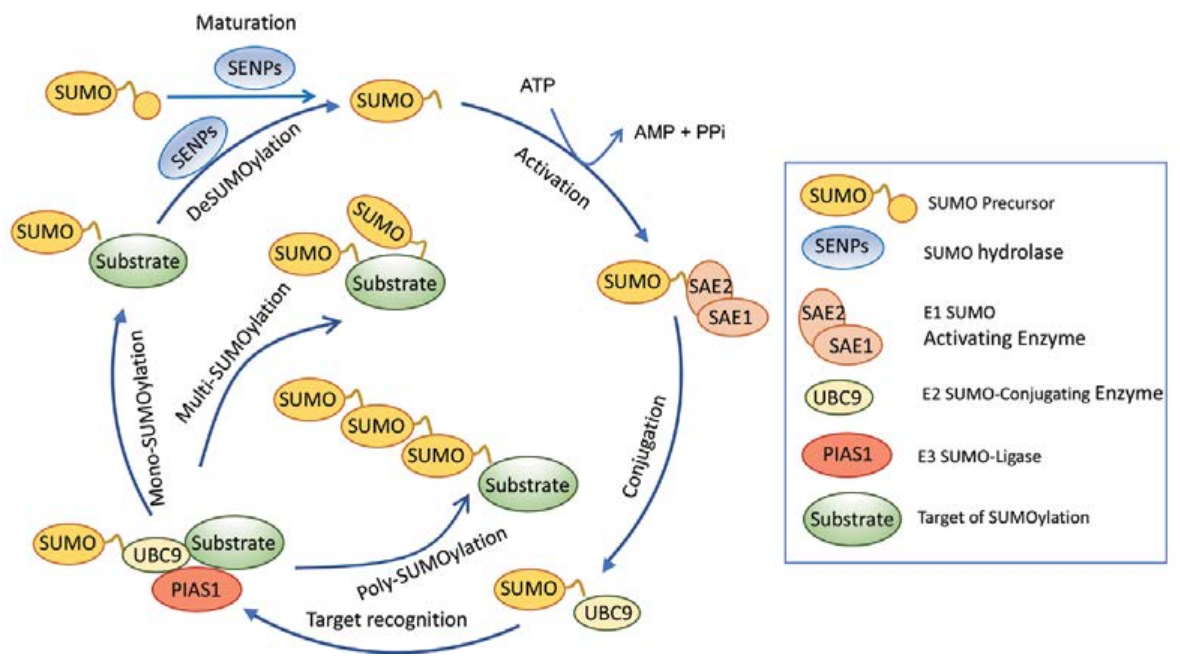

Figure 14.4 Posttranslational modification by SUMOylation. A schematic representing the various steps involved in the SUMOylation and deSUMOylation cycle. SUMO E1, E2 and E3 enzymes (mammalian representative of these enzymes is shown) promote the conjugation of SUMO to substrate proteins. DeSUMOylation is catalysed by SUMO-specific proteases [mammalian SENPs (Sentrin/SUMO-specific proteases) is shown as a representative example] and is involved both in SUMO maturation and in the removal of SUMO moieties from protein substrates. 


\section{SUMO-dependent regulation of replication initiation}

\section{Overview of the SUMOylation process}

Modification via the small ubiquitin-like molecule SUMO (Fig. 14.4) also plays important roles in the regulation of eukaryotic DNA replication as well as the regulation of multiple other cellular activities including DNA repair, transcription, nuclear transport, and protein quality control (Sarangi and Zhao, 2015; Jalal et al., 2017; Zilio et al., 2017). Similar to ubiquitination, sumoylation involves the covalent conjugation of SUMO or SUMO chains to the $\varepsilon$ amino-group Lys residue of substrates, and requires the sequential action of $\mathrm{E} 1$ activating, E2 conjugating, and E3 ligase enzymes (Johnson, 2004; Gareau and Lima, 2010; Lamoliatte et al., 2014), reminiscent of that involved in protein ubiquitination. SUMO, like ubiquitin, is usually conjugated to Lys side chains of substrate protein and can be conjugated at single Lys in the substrate proteins (mono-sumoylation), at multiple Lys residues of the substrate proteins (multi-sumoylation), or form various length chains at single Lys in the protein substrates (poly-sumoylation) (Fig. 14.4).

Like ubiquitination, protein modification by sumoylation is reversible and is regulated by a set of SUMO-specific cysteine proteases (Mukhopadhyay and Dasso, 2007; Hickey et al., 2012). SUMO proteases deconjugate SUMO proteins using their isopeptidase activity, cleaving between the terminal Gly of SUMO and the substrate Lys (Hickey et al., 2012). The first described SUMO protease, the $S$. cerevisiae protein U1p1 (UBL-specific protease 1), exhibits distant similarity to certain viral proteases but is unrelated to any known deubiquitinating enzyme ( $\mathrm{Li}$ and Hochstrasser, 1999). Mammalian cells express at least six SUMO-specific proteases, known as SENPs or Sentrin/SUMO-specific proteases (SENP1-SENP3 and SENP5-SENP7), that share significant sequence homology with U1p1, and can be broadly classified into three subfamilies based on their sequence homology, subcellular localization and substrate specificity (Mukhopadhyay and Dasso, 2007; Hickey et al., 2012). Three additional SUMO-specific proteases, DESI1 (deSUMOylating isopeptidase 1), DES12 and USPL1 (ubiquitin-specific protease-like) exist in mammalian cells and share only little sequence similarity to U1P or SENPs (Schulz et al., 2012; Shin et al., 2012). Some SUMO-specific proteases are also important for SUMO maturation, as they cleave the precursor or inactive form of SUMO at the c-terminus to expose two glycine residues. SUMO proteases play important roles in protein-protein interaction and in regulating cellular localization, and significant effort is dedicated for the development of pharmacological inhibitors of this class of proteases for therapeutic purposes (Mukhopadhyay and Dasso, 2007; Hickey et al., 2012; Kumar and Zhang, 2015; Bialik and Woźniak, 2017).

\section{Regulation of replication initiation proteins via SUMOylation}

As is the case for ubiquitination, modification of replication initiation proteins by sumoylation helps restrict origin licensing to late mitosis and early G1. Initial studies in budding yeast demonstrated that multiple subunits of the ORC complex undergo sumoylation, although the functional significance of these modifications is not entirely clear (Cremona et al., 2012). Studies of human ORC2 demonstrated that this subunit is sumoylated in G2/M. ORC2 sumoylation restricts the ORC complex to centromeric regions within the genome and enhances the demethylation of histone $\mathrm{H} 3$ lysine 4 (H3K4) in centromeric chromatin via the recruitment of the H3K4 demethylase KDM5A (Craig et al., 2003; Prasanth et al., 2004; Lee et al., 2012; Huang et al., 2016). Inhibition of ORC2 sumoylation results in rereplication, polyploidy and DNA damage at centromeric chromatin that correlate with the accumulation of $\mathrm{H} 3 \mathrm{~K} 4$ trimethylation (H3K4me3) in centromeric chromatin, reduced transcription from centromeric $\alpha$-Satellites, and replication from decondensed pericentric heterochromatin (Huang et al., 2016). It remains to be seen whether the sumoylation of other ORC subunits or ORC2 from the other eukaryotes play a specialized role in the regulation of origin licensing as that seen for human ORC2 or exhibit similar, generalized, and, possibly, redundant function in preventing relicensing of replication origins from centromeric heterochromatin through promoting epigenetic changes. 
Similar to ORCs, multiple subunits of the MCM2-7 complex from various eukaryotes were found to be sumoylated (Golebiowski et al., 2009; Elrouby and Coupland, 2010; Cremona et al., 2012; Hendriks et al., 2014; Ma et al., 2014; Schimmel et al., 2014; Tammsalu et al., 2014; de Albuquerque et al., 2016; Wei and Zhao, 2016). MCM2-7 sumoylation appears to also negatively regulate replication initiation. This is supported by the finding that, in both man and yeast, the sumoylation of the six-subunit complex is detectable in G1, preceding DDK1-mediated phosphorylation of the MCM4 subunit, but is rapidly declined as cells enter $S$ phase and remains undetectable until the G1 of the next cycle; the exception is with the yeast $\mathrm{Mcm} 7$ subunit, which persists throughout $S$ phase and peaks with the completion of replication (Cremona et al., 2012; Schimmel et al., 2014; de Albuquerque et al., 2016; Wei and Zhao, 2016). Studies in yeast demonstrate that Mcm2-6 sumoylation increases its association with the PP1 phosphatase, thereby preventing premature phosphorylation of $\mathrm{Mcm} 4$, an essential step for CMG formation and origin firing (Davé et al., 2014; Hiraga et al., 2014; Mattarocci et al., 2014; Wei and Zhao, 2016). At the G1/S transition, and as cells enter S phase, the DDK kinase activity rises, and this, combined with Mcm2-6 desumoylation, potentially via the Ulp2 protease (de Albuquerque et al., 2016; Wei and Zhao, 2016), aid in Mcm4 phosphorylation, CMG activation, and origin firing (Wei and Zhao, 2016). A further evidence in support of a negative role for sumoylation in the regulation of replication initiation in eukaryotes is obtained from a study in Xenopus, where the expression of SUMO-specific proteases or a dominant-negative SUMO E2 was found to increase origin firing (Bonne-Andrea et al., 2013). Because the PPIDDK-mediated regulation of MCM2-7 activation is conserved across eukaryotic species (Wotton and Shore, 1997; Lee et al., 2003; Cho et al., 2006; Masai et al., 2006; Montagnoli et al., 2006; Tsuji et al., 2006; Cornacchia et al., 2012; Hayano et al., 2012; Yamazaki et al., 2012), these studies support the conclusion that negative regulation of MCM2-7 phosphorylation through sumoylation is an evolutionary conserved mechanism that regulates replication initiation in eukaryotes.

\section{Ubiquitin and SUMO regulation of DNA synthesis}

\section{Proteolytic and non-proteolytic roles for ubiquitin and SUMO at the replisome}

Emerging evidence support important roles for protein ubiquitination and sumoylation in the regulation of unperturbed DNA synthesis (Fig. 14.5), as well as in coordinating DNA synthesis with chromatin dynamics (Almouzni and Cedar, 2016; García-Rodríguez et al., 2016; Henikoff, 2016; Talbert and Henikoff, 2017). Proteomic analysis demonstrated that many of the components of the replisome were found to be ubiquitinated (Wagner et al., 2011). Although ubiquitination plays both proteolytic and non-proteolytic functions during DNA synthesis, sumoylation of replisome components almost invariably plays only nonproteolytic regulatory roles. The non-proteolytic regulatory functions of ubiquitin and SUMO are not always apparent, although in some cases their role is beginning to be appreciated. For example, the catalytic subunit of polymerase $\delta$ in the fission yeast Saccharomyces Pombe is stable despite undergoing ubiquitination in unperturbed $S$ phase (Roseaulin et al., 2013). Pol2, the catalytic subunit of DNA polymerase $\varepsilon$, however, is ubiquitinated and degraded via the $\mathrm{SCF}^{\mathrm{Pof} 3}$ ligase (Roseaulin et al., 2013). This implies that the synthesis of the leading strand requires a 'fresh' supply of DNA polymerase, whereas the synthesis of the discontinuous lagging strand does not (Roseaulin et al., 2013). In mammalian cells, both regulatory subunits of DNA polymerase $\delta$ (POL $\delta$ ), p66 and $\mathrm{p} 12$, are ubiquitinated during $S$ phase, and this modification appears to regulate protein-protein interactions either within the polymerase holoenzyme or with other replication factors (Liu and Warbrick, 2006). Interestingly, the suppression of fork progression in response to DNA damage is mediated, at least in part, through ubiquitin-dependent proteolysis of the p12 subunit via the CRL4 ${ }^{\mathrm{CDT} 2}$ ligase, which requires the interaction of $\mathrm{p} 12$ with PCNA (Terai et al., 2013). This is only one of the several examples of the role of UPS in regulating DNA replication under replication stress or in response to DNA damage, which are described in greater details in several recent outstanding reviews (Sommers et al., 

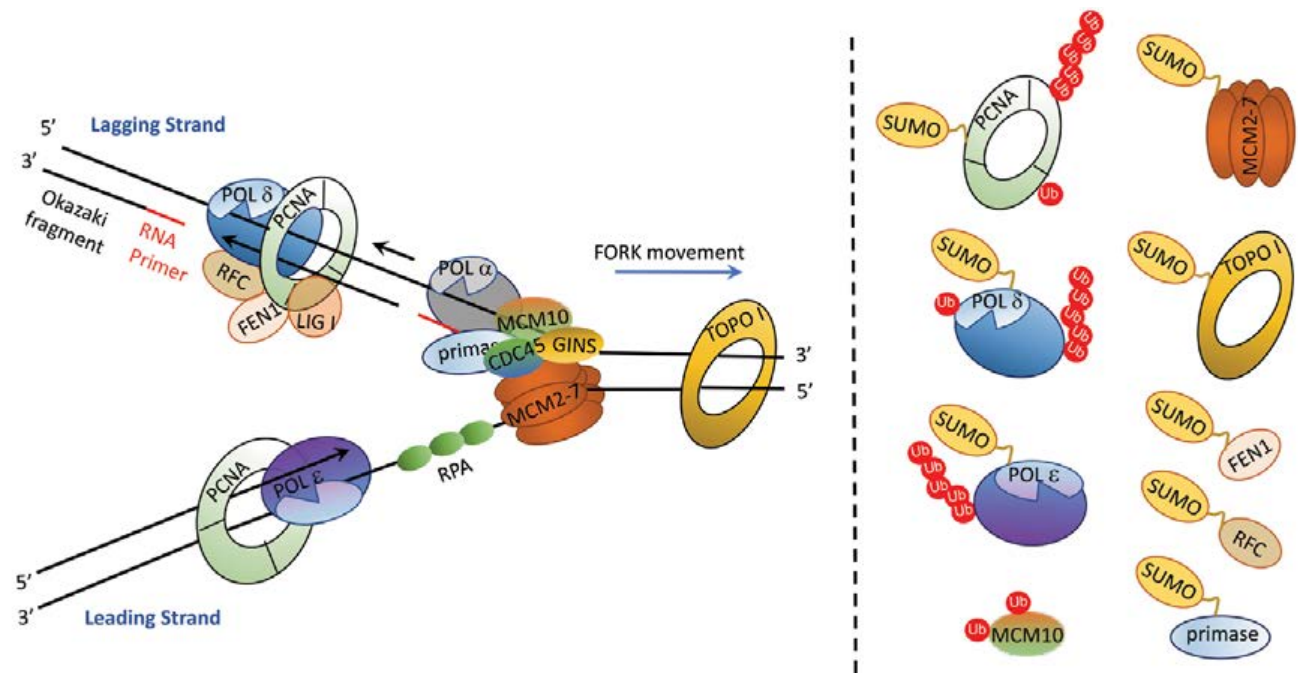

Figure 14.5 Ubiquitin and SUMO regulation of DNA synthesis. A schematic model of the replication fork during DNA synthesis in eukaryotic cells. The CMG replicative helicase (MCM2-7/GINS/CDC45) unwinds the duplex DNA ahead of the replication fork. Topoisomerase TOPO I is important for the relaxation of the positive supercoiling building ahead of the replication fork. TOPO II (not shown) can resolve the intertwining of the daughter DNA strands resulting from the fork rotation behind the replication fork. Single-stranded DNA (ssDNA) is coated by the ssDNA binding protein RPA (replication protein A). The replication factor C (RFC) loads PCNA and DNA polymerase $\varepsilon(P O L \varepsilon$ ) to synthesize the leading strand (continuous replication). On the lagging strand, DNA polymerase a (POL a), which is stabilized by the Minichromosome maintenance protein 10 (MCM10), synthesizes short RNA/DNA primer. RFC subsequently displaces POL a, and polymerase $\delta$ (POL $\delta$ ) synthesizes short DNA segments (Okazaki fragments). The flap structure-specific endonuclease FEN1 processes the $5^{\prime}$ ends of Okazaki fragments, and the DNA ligase I (LIG I) joins the DNA fragments (discontinuous replication). Many of these proteins (shown on right) are modified by ubiquitination and SUMOylation and this is important for the regulation of DNA synthesis (see text for details).

2015; García-Rodríguez et al., 2016; Renaudin et al., 2016).

Another replisome protein that undergoes both proteolytic and non-proteolytic ubiquitination is the minichromosome maintenance protein 10 (MCM10). Mcm10 was first identified by Lawrence Dumas and colleagues in a screen for temperaturesensitive mutants for $S$ phase progression defects in S. cerevisiae and denoted as dna43 (Dumas et al., 1982). MCM10 was subsequently identified (and the gene sequenced) in an independent study aimed at identifying replication initiation mutants that are defective in the maintenance of minichromosomes (Merchant et al., 1997). MCM10 is an essential DNA replication factor and is conserved in all eukaryotes but is absent in bacteria and archaea. The protein functions primarily as a scaffold protein with DNA binding properties but lacks enzymatic functions. Initial studies in fission yeast demonstrated that $\mathrm{Mcm} 10 / \mathrm{Cdc} 23$ plays a role in replication initiation through facilitating Cdc45 chromatin binding, an essential step in CMG activation (Gregan et al., 2003). Subsequent studies showed that Mcmlo facilitates the initial strand separation through its binding to origins through its Zink finger-dependent DNA binding activity (Kanke et al., 2012; van Deursen et al., 2012; Thu and Bielinsky, 2013). In budding yeast, Mcm10 appears to play an additional role in replication elongation through interacting with and stabilizing the catalytic subunit of DNA polymerase $\alpha$ (Pol1) (Ricke and Bielinsky, 2004). In G1 and in S phase, the budding yeast Mcm 10 undergoes mono-ubiquitination at two Lys residues (diubiquitination) and this was shown to be essential for its interaction with PCNA and for cell growth (Das-Bradoo et al., 2006; Thu and Bielinsky, 2013). Similar to budding yeast, mammalian MCM10 interacts with and stabilizes the catalytic subunit of DNA POL $\alpha$ (p180) (Fig. 14.5), and this is important for efficient DNA 
synthesis (Chattopadhyay and Bielinsky, 2007; Zhu et al., 2007). Whether mammalian MCM10 undergoes di-ubiquitination, and if this regulates its ability to interact with PCNA or with other components of the replisome is not known. Mammalian MCM10 however, was shown undergo ubiquitindependent degradation both in unperturbed cells and following exposure to of cells to ultraviolet radiation (UV) (Kaur et al., 2012; Romani et al., 2015). Although MCM10 degradation following DNA damage may be important to halt DNA synthesis in the face the bulky DNA lesions induced by $\mathrm{UV}$, the significance of its proteolytic degradation during unperturbed $S$ phase remains to be determined.

Systematic and proteome-wide proteomic studies demonstrate that many of the replisome proteins that are regulated via the UPS are also sumoylated (Cremona et al., 2012; Tammsalu et al., 2014; Bursomanno et al., 2015). Similar enrichment for poly-sumoylated proteins during DNA synthesis is also observed using an in vitro replication assay in Xenopus egg extract (BonneAndrea et al., 2013). Additional studies utilizing a method of isolating proteins on nascent DNA coupled with mass spectrometry (iPOND-MS) also demonstrate that chromatin isolated within the vicinity of the replisome is significantly enriched for sumoylated proteins (Lopez-Contreras et al., 2013; Dungrawala et al., 2015). These studies also demonstrated a relative depletion of ubiquitination events, suggesting an interaction between ubiquitination and sumoylation at the replisome. The identity of the E3 SUMO ligase responsible for protein sumoylation at the replisome is not known, but PIAS1 is a good candidate given its enrichment at these active replicating sites (Lecona et al., 2016). The USP7/HAUSP (Herpesvirusassociated ubiquitin-specific protease) DUB is another protein that is enriched at active DNA synthesis sites and may be responsible for the observed depletion of ubiquitinated proteins (Lecona et al., 2016). USP7 is a SUMO-DUB (SDUB), and is one of only two DUBs (the other is USP11) that have been shown to deubiquitylate sumoylated proteins (Hendriks et al., 2015; Lecona et al., 2016). Pharmacological inhibition of USP7 slows replication fork progression, inhibits new origin firing, and reverses the high-SUMO and low-ubiquitin chromatin environment observed at or near the replisome (Bonne-Andrea et al., 2013; Lopez-Contreras et al., 2013; Lecona et al., 2016). How USP7 regulates new origin firing and replication progression is not entirely clear, but likely dependent on the stabilization of sumoylated replisome components that are essential for the replisome activity (Lecona et al., 2016; Wei and Zhao, 2016). This conclusion is substantiated by the reduced replication progression in SUMO E2 and E3 mutants as well as by the prolonged $S$ phase progression seen in human cells with inactivated UBC9 SUMO-conjugating enzyme (Cremona et al., 2012; Schimmel et al., 2014; Hang et al., 2015). These studies, however, do not exclude the possibility that the accumulation of ubiquitinated proteins (or their ubiquitin-dependent degradation) upon USP7 inhibition may contribute to the inhibition of replication progression or new origin firing.

One of the most notable examples of replisome proteins that is regulated by sumoylation is the budding yeast Pol2. Pol2 sumoylation is mediated by the Nse2/Mms21 SUMO ligase, and this sumoylation, as well as the sumoylation of $\mathrm{Mcm} 6$, is reduced not only in cells with mutations in Nse2, but also in cells deficient in Rtt107, a multi-functional scaffolding protein that plays multiple roles in replication progression (Hang et al., 2015). Although the main function of Pol2 sumoylation is not entirely clear, it is tempting to speculate that it may have important regulatory role for controlling DNA polymerase activity during replication fork progression. Significantly, the Nse2/Mms21 SUMO ligase, along with the Ubc9 SUMO-conjugating enzyme, also plays a role for the sumoylation of Smc5 and Smc6 subunits of the SMC (structural maintenance of chromosomes) SMC5/6 complex, and this is important for the repair of collapsed replication forks and for counteracting recombinogenic events at damaged replication forks (Ampatzidou et al., 2006; Branzei et al., 2006; Chen et al., 2009; Xue et al., 2014). Interestingly, Rtt107, which plays an important role in cellular response to replication stress to reduce replication-associated recombination, forms two additional and distinct complexes with the cullin $4 \mathrm{E} 3$ ubiquitin ligase Rtt101 ${ }^{\mathrm{Mms22}}$ (Collins et al., 2007; Hang and Zhao, 2016; Xue et al., 2014), and with the Slx4 scaffolding protein (Hang and Zhao, 2016). The Rtt101 ${ }^{\mathrm{Mms} 22}$ ubiquitin ligase ubiquitylates acetylated histone $\mathrm{H} 3$, and this facilitates nucleosome assembly during replication 
(Han et al., 2013). The Rtt107-Slx4 complex on the other hand, is critical for controlling recombination during DNA replication, particularly under conditions of replicative stress (Chin et al., 2006; Roberts et al., 2006; Ohouo et al., 2010). The Ataxia telangiectasia related protein kinase ATR and the checkpoint protein $\mathrm{CHK} 1$ play important roles in stabilizing stalled replication forks and for preventing their collapse into DSBs. In mammalian cells, the generation of DSBs following ATR inhibition is dependent on the SLX4 scaffold endonuclease, and requires the activity of the RNF4E3 ubiquitin ligase that promotes the ubiquitin-dependent degradation of sumoylated proteins at stalled replication forks (Ragland et al., 2013). Interestingly, RNF4 also promotes the polyubiquitination of activated Fanconi anaemia proteins FANCD2 and FANCI following their ATR-dependent sumoylation by the SUMO E3 ligases PIAS1/PIAS4 at stalled replication forks (Gibbs-Seymour et al., 2015). Ubiquitinated FANCD2 and FANC1 are subsequently removed from the stalled replication sites through the activity of the DVC1-p97 segregase complex, and inactivation of FANCD2/FNACI sumoylation compromises cell survival in response to replication stress (Gibbs-Seymour et al., 2015). This example highlights the interplay between sumoylation and ubiquitination in the regulation of DNA replication at active replication sites both during normal replication and in response to replication stress.

In addition to undergoing mono-ubiquitinated, the p66 subunit of the mammalian DNA POL $\delta$ is also mono-sumoylated by SUMO3, and this modification likely regulates protein-protein interaction or impacts the polymerase function (Liu and Warbrick, 2006). Other proteins involved in the synthesis of DNA lagging strand, such as the flap endonuclease 1 protein (FEN1), also undergoes sumoylation. FEN1 sumoylation in human cells is mediated by SUMO3 and begins in S phase and peaks in G2/M (Guo et al., 2012). FEN1 sumoylation promotes its ubiquitination and degradation via the PRP19 E3 ligase, which interacts with sumoylated FEN1 at least in part through its SIM (sumo-interacting motif) motif (Guo et al., 2012). Interestingly mutation of Ser-187 in FEN1 to Ala abrogates the phosphorylation at this site and precludes FEN1 sumoylation resulting in cell cycle delay and polyploidy (Guo et al., 2012).
In addition to the various components of the replicative helicases and polymerases, other components of the replisomes, including topoisomerases, DNA primase, the clamp loader RFC complex, as well as the nucleosome remodelling factor FACT were also found to be sumoylated (Golebiowski $e t$ al., 2009; Elrouby and Coupland, 2010; Cremona et al., 2012; Ma et al., 2014; Tammsalu et al., 2014). Among these, the sumoylation of DNA topoisomerase (TOP1) is best understood. The PIAS1 SUMO ligase was recently shown to sumoylate TOP1, and this is essential for reducing R-loop-mediated stalling of replication forks ( $\mathrm{Li}$ et al., 2015). Biochemically, TOP1 sumoylation inhibits its catalytic activity, thereby reducing the nicking of DNA at transcriptionally active sites ( $\mathrm{Li}$ et al., 2015). TOP1 sumoylation also enhances its binding to active RNA polymerase II, resulting the recruitment of splicing factors to suppress R-loop formation (Li et al., 2015). The role of sumoylation and/or ubiquitination in the regulation of other replisome components as well as other complexes involved in replication progression, such as components of the SMC complex (e.g. cohesin, condensin), is less understood, although emerging evidence support an important role for sumoylation in cohesion establishment (Rudra and Skibbens, 2013).

\section{PCNA: A central hub for ubiquitination and SUMOylation signalling}

One of the best examples for the role of ubiquitination and sumoylation in the regulation of DNA replication progression involves PCNA (Fig. 14.5). The homotrimeric DNA polymerase sliding-clamp coordinates the activity of many proteins involved in DNA replication, DNA repair and other chromatinrelated transactions (Choe and Moldovan, 2017; Ulrich and Takahashi, 2013). Although PCNA can be ubiquitinated at multiple Lys residues (McIntyre and Woodgate, 2015), only the mono-ubiquitination of PCNA at a conserved Lys residue (Lys-164 in human PCNA) is well understood. This particular modification is carried out by the Rad6-Rad18 E2-E3 ubiquitin conjugating enzyme/ligase and is one of the best understood posttranslational modifications of this protein. Such modification impacts the affinity of PCNA for different DNA polymerases, and is essential for error-prone translesion DNA synthesis (TLS) through the recruitment 
of translesion Y-family DNA polymerases [e.g. polymerase eta $(\mathrm{POL}-\eta)]$ to replication factories to bypass replication-stalling DNA lesions (Yang et al., 2013). This recruitment is dependent on the ubiquitin-binding domain of TLS polymerases, which has a high-affinity to mono-ubiquitinated PCNA (Bienko et al., 2005; Plosky et al., 2006). The CRL4 ${ }^{\mathrm{CDT} 2}$ and RNF8 ubiquitin ligases are two other E3 ligases that can substitute for Rad18 in promoting PCNA mono-ubiquitination (Zhang et al., 2008; Terai et al., 2010). Although this posttranslational modification is significantly stimulated in cells exposed to bulky DNA lesions, such as those induced by UV (e.g. cyclobutane pyrimidine dimers), mono-ubiquitinated PCNA is detectable in normal proliferating cells in the absence of DNA damage, perhaps to aid in the replication of difficult to replicate DNA sequences or to cope with replication stress (Leach and Michael, 2005; Frampton et al., 2006; Terai et al., 2010).

In $S$. cerevisiae, the heterodimeric E2 ubiquitin conjugating enzyme, Ubc13-Mms2, which is recruited to chromatin by the RING-finger protein Rad5, can convert the mono-ubiquitinated Lys on PCNA to Lys-63-linked polyubiquitin chain to participate in gap-filling damage tolerance (Prakash, 1981; Hoege et al., 2002; Torres-Ramos et al., 2002; Branzei et al., 2004; Haracska et al., 2004) and in template switching, an error-free pathway of DNA that utilizes the newly replicated sister chromatid as a template for replication (Hoege et al., 2002; Branzei et al., 2008, 2011; Choi et al., 2010; Hedglin and Benkovic, 2015).

In mammals, this biochemical activity is carried out by the SNF2 histone linker plant homeodomain RING helicase (SHPRH) or by the helicase-like transcription factor (HLTF), and this was shown to suppress PCNA-dependent TLS and mutagenesis (Motegi et al., 2008; Unk et al., 2008). Interestingly, RAD18 itself can be mono-ubiquitinated, and this PTM inhibits its ability to mono-ubiquitylate PCNA and, the same time, suppresses its interaction with SHPRH or HLTF (Lin et al., 2011; Moldovan and D'Andrea, 2011; Zeman et al., 2014). Template switching is further facilitated by USP7, which deubiquitinates and stabilizes both HLTF and RAD18 through enhancing the interaction between the non-ubiquitinated RAD18 and HLTF (Qing et al., 2011; Zeman et al., 2014). Under replicative stress (e.g. following treatment with the alkylating agent methyl methanosulfonate (MMS)), USP7 also deubiquitinates and stabilizes both RAD18 and POL- $\eta$, and this promotes TLS (Qian et al., 2015; Zlatanou et al., 2016). Under these conditions, the E3 ubiquitin ligase TNF receptor associated factor (TRAF)-interacting protein (TRIP) also facilitates TLS by promoting the Lys-63-polyubiquitination of POL- $\eta$, which is required for its focus formation at damage sites (Wallace et al., 2014).

Several activities restrain TLS activity to reduce or prevent the mutagenic load caused by the lowfidelity polymerases. USP7 likely plays a role in this regulatory step by removing the mono-ubiquitin moiety on PCNA (Kashiwaba et al., 2015). The isopeptidase USP1, however, plays a more prominent role in deubiquitinating PCNA and in turning off TLS (Huang et al., 2006; Andersen et al., 2008). TLS is also restrained under conditions of increased DNA damage by UV irradiation, and this is mediated by USP10, which also deubiquitinates PCNA (Park et al., 2014). USP10-dependent PCNA deubiquitination requires the activity of EFP, an ISG15 E3 ligase, which ISGylate monoubiquitinated PCNA, thereby recruiting USP10 to deubiquitylate PCNA (Park et al., 2014). Following the release of POL- $\eta$, PCNA is de-ISGylated by UBP43, and engages the replicative DNA polymerases to resume normal replication, and inactivation of this pathway increases mutagenesis. In yeast, however, increased PCNA mono-ubiquitination, for example through inactivating the PCNA deubiquitinase Ubp10, does not increase mutagenesis, suggesting the existence of other mechanisms to suppress TLS (Gallego-Sanchez et al., 2012). The TLS polymerases themselves are subject to proteolytic degradation, and in the case of POL- $\eta$, this is mediated by MDM2 (Jung et al., 2012). POL- $\eta$ can also be mono-ubiquitinated by the PIRH2 E3 ligase, and this suppresses its interaction with mono-ubiquitinated PCNA (Jung et al., 2010, 2011). Inactivation of TLS polymerases through ubiquitination is also conserved in yeast. For example, the S. cerevisiae homologue of POL- $\eta$, Rad30, as well as the Rev1 polymerase undergo proteolytic degradation, and for Rad30, this is mediated via the SCF Ufol ubiquitin ligase (Waters and Walker, 2006; Skoneczna et al., 2007; Plachta et al., 2015).

Sumoylation also plays important roles for regulating PCNA function. In fact, PCNA is sumoylated at the same Lys residue that is 
subject to mono-ubiquitination, suggesting that both sumoylation and ubiquitination of the same residue on PCNA is tightly regulated for optimal activity of this important protein. In yeast, PCNA sumoylation on Lys-164 (and to a lesser extent on Lys-127) is cell cycle regulated, preceding the entry of cells into S-phase, and is robustly induced by severe or lethal DNA damage (Hoege et al., 2002; Branzei, 2011; Hedglin and Benkovic, 2015). PCNA sumoylation, which is catalysed by the Ubc9 SUMO-conjugating enzyme, appears to interfere with PCNA-polymerase binding and with DNA repair, and is likely to be important for unloading PCNA during normal replication (Hoege et al., 2002; Branzei, 2011; Hedglin and Benkovic, 2015). Inactivation of UBC9 function in human cell lines prolongs $S$-phase, but it is unclear whether this is due to suppression of PCNA sumoylation (Schimmel et al., 2014). PCNA sumoylation is also important for the recruitment of the Srs2 helicase and anti-recombinase to suppress spontaneous and DNA damage-induced homologous recombination during S phase (Papouli et al., 2005; Pfander et al., 2005; Armstrong et al., 2012; García-Rodríguez et al., 2016; Zilio et al., 2017). Inactivation of PCNA sumoylation was also shown to suppress post-replication repair associated with template switching (Branzei et al., 2008), and this likely due to interference between SUMO-PCNA interaction with Srs2 and/or with Rad18, Rad5 and ELg1 (an alternative subunit of the RFC clamp loader) (Pfander et al., 2005; Parnas et al., 2010). Sumoylation of mammalian PCNA is less abundant (Gali et al., 2012), reflecting the lower recombination activity in mammals.

\section{Regulation of replication termination by ubiquitin and SUMO}

How eukaryotic DNA replication is terminated is not entirely clear, but emerging evidence support important roles for ubiquitination in this process (Fig. 14.6). Studies in budding yeast and in Xenopus egg extracts show that the disassembly of the CMG complex is dependent on Lys-48-linked polyubiquitination of the MCM7 subunit of the MCM2-7 helicase (Maric et al., 2014; Moreno et al., 2014). Ubiquitinated MCM7 is recognized by the hexameric AAA+ adenosine triphosphatase (ATPase) and the segregase Cdc48/p97, which

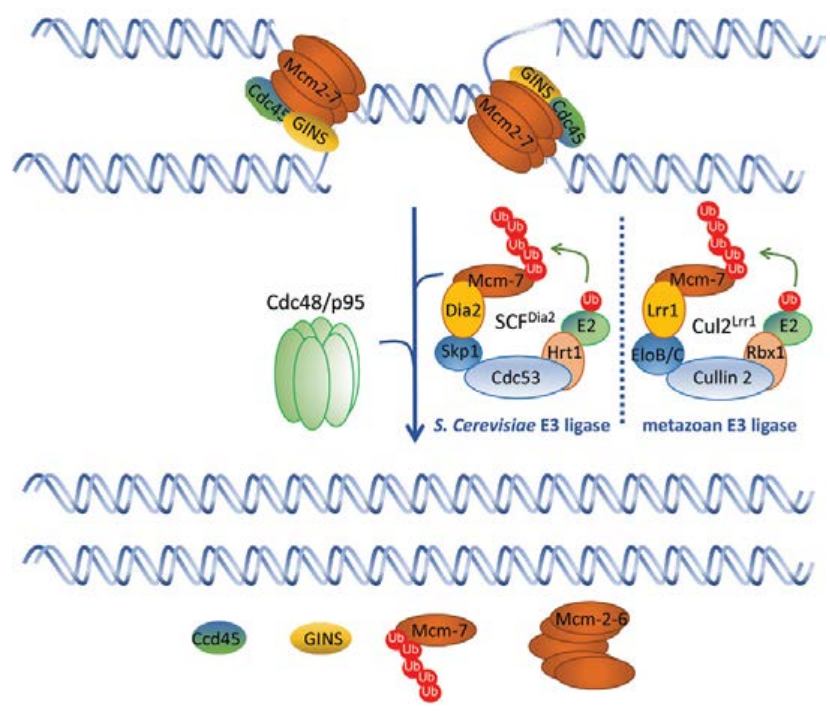

Figure 14.6 Ubiquitin-dependent regulation of replication termination in eukaryotes. A model depicting the termination of eukaryotic DNA replication at converging replication forks, and its regulation by the ubiquitination of the Mcm7 Subunit of the Mcm2-7 helicase complex leading to the disassembly of the CMG complex (Mcm27-GING-Cdc45). Mcm7 ubiquitination is promoted by the SCFDia2 E3 ubiquitin ligase in S. cerevisiae and by the CRL2 ${ }^{\mathrm{Lr} r 1} \mathrm{E} 3$ ubiquitin ligase in metazoans and is extracted through the activity of the p97 chaperon. 
on ATP hydrolysis promotes protein unfolding (Barthelme et al., 2014; Maric et al., 2014; Moreno et al., 2014). This triggers MCM7 translocation through the $\mathrm{Cdc} 48 / \mathrm{p} 97$ ring, with the consequent disassembly of the hexameric MCM2-7 complex and replication termination (Bell, 2014; Lengronne and Pasero, 2014). $\mathrm{Mcm} 7$ polyubiquitination in S. cerevisiae is mediated by the SCF E3 ligase and the F-box protein Dia2, and inactivation of this pathway prevents CMG disassembly resulting in replication defects, although $\mathrm{Mcm} 2$ proteolysis is not required for Mcm2-7 disassembly and replication termination (Maric et al., 2014; Moreno et al., 2014; Morohashi et al., 2009). Polyubiquitination of the MCM7 in C. elegans and in Xenopus, is carried out by the replisome associated ubiquitin ligase $\mathrm{CRL} 2^{\mathrm{Lrrl}}$, which is similarly required for replication termination (Dewar et al., 2017; Sonneville et al., 2017). A role for protein sumoylation is replication termination is also beginning to emerge. In $S$. cerevisiae for example, the termination of DNA replication is associated with a specific reduction in $\mathrm{Mcm} 7$ sumoylation, which unlike the sumoylation of the other Mcm2-6 subunits, is concordant with the completion of DNA replication concurrent with increases in polyubiquitination of this subunit. (Wei and Zhao, 2016). It remains to be determined if the sumoylation of $\mathrm{Mcm} 7$ interferes with or is coordinated with the polyubiquitination of this subunit and with replication termination. As mentioned above, the Top2 DNA topoisomerase in budding yeast has been implicated in promoting replication across TERs, and this is important for the merging of the converging replication forks at these replication termination sites (Fachinetti et al., 2010). Top2 is also important for the decatenation of sister chromatids (Lee and Bachant, 2009). Interestingly, a subset of Topo II in various eukaryotes, including human TOPO II, is found to be sumoylated. In mitosis, the sumoylation of metazoan Topo II is essential for its recruitment to kinetochores, and interference with this sumoylation results in elevated frequency of segregation errors and aneuploidy (Lee and Bachant, 2009). A similar function for Topo II sumoylation in promoting replication termination is expected, but a concrete evidence for this prediction is yet to emerge.

\section{Concluding remarks}

Significant advances in our understanding of the molecular and biochemical activities that function to control DNA replication have been made in the last few decades. The identification and characterization of the various PTMs of the many proteins that are associated with almost every step of DNA replication enriched our appreciation of the complexity underlying this highly conserved and important biological activity. In particular, the covalent attachment of ubiquitin and/or the ubiquitin-related protein SUMO on specific Lys residues on replication and replication-related proteins to form monomers and polymers of ubiquitin or SUMO chains ensures the timely and efficient temporal and spatial control of replication both during normal proliferation and in response to various perturbations. Modification of replication proteins by ubiquitin and SUMO involves both proteolytic and non-proteolytic functions that operate cooperatively through convoluted feedback mechanisms that, together with other PTMs, provide rich and complex networks of protein-protein communications to control both the fidelity and robustness of DNA replication. The execution of these modifications by a diverse and highly specific set of E2-E3 pairs of ubiquitin and SUMO conjugating enzymes and ligases, as well as their reversal by an equally diverse and specific set of ubiquitin- and SUMO-proteases, adds a readily apparent new layer of complexity that will require significant more research to fully understand and appreciate. While we know a great deal about the mechanisms involved in the ubiquitination and sumoylation of replication proteins and their impact on replication, proteome-wide studies indicate that many more replication and replication-related proteins are modified by these versatile moieties, both during normal replication and in response to cellular stresses, particularly those that cause replication stress. For these, the challenge is to understand the functional significance of these additional modifications and to identify the biochemical activities underlying their regulation. It is expected that new breakthroughs will come to be soon realized given the recent development of novel state-of-art biochemical protocols and assays (e.g. iPOND-MS and proximity labelling 
assays), gene-specific editing tools (e.g. CRISPR/ Cas and TALENs) as well as new genetic screening and functional assays. Lessons from past research, as outlined in this review, indicate that few family members of the ubiquitin and SUMO conjugating and deconjugating enzymes, such as the SCF, $\mathrm{APC} / \mathrm{C}$ and CRL4 ubiquitin ligases, the USP7 deubiquitinase, the UBC9 SUMO conjugating enzyme as well as the SUMO ligase PIAS1, play key role in the regulation of the various aspects of eukaryotic DNA replication. These will likely to dominate the scene in future research in this area.

\section{Acknowledgement}

We apologize for authors whose primary work was not cited due to space limitations. Work in the author's laboratory is supported by NIH grant R00 CA140774.

\section{References}

Abbas, T., and Dutta, A. (2009). p21 in cancer: intricate networks and multiple activities. Nat. Rev. Cancer 9, 400-414. https://doi.org/10.1038/nrc2657.

Abbas, T., and Dutta, A. (2011). CRL4Cdt2: master coordinator of cell cycle progression and genome stability. Cell Cycle 10, 241-249.

Abbas, T., and Dutta, A. (2017). Regulation of mammalian DNA replication via the ubiquitin-proteasome system. Adv. Exp. Med. Biol. 1042, 421-454. https://doi. org/10.1007/978-981-10-6955-0_19.

Abbas, T., Sivaprasad, U., Terai, K., Amador, V., Pagano, M., and Dutta, A. (2008). PCNA-dependent regulation of p21 ubiquitylation and degradation via the CRL4Cdt2 ubiquitin ligase complex. Genes Dev. 22, 2496-2506. https://doi.org/10.1101/gad.1676108.

Abbas, T., Shibata, E., Park, J., Jha, S., Karnani, N., and Dutta, A. (2010). CRL4(Cdt2) regulates cell proliferation and histone gene expression by targeting PR-Set7/ Set8 for degradation. Mol. Cell 40, 9-21. https://doi. org/10.1016/j.molcel.2010.09.014.

Abbas, T., Keaton, M.A., and Dutta, A. (2013). Genomic instability in cancer. Cold Spring Harb. Perspect. Biol. 5, a012914. https://doi.org/10.1101/cshperspect. a012914.

Alexandrow, M.G., and Hamlin, J.L. (2004). Cdc6 chromatin affinity is unaffected by serine-54 phosphorylation, S-phase progression, and overexpression of cyclin A. Mol. Cell. Biol. 24, 1614-1627.

Almouzni, G., and Cedar, H. (2016). Maintenance of epigenetic information. Cold Spring Harb. Perspect. Biol. 8, a019372. https://doi.org/10.1101/cshperspect. a019372.

Amador, V., Ge, S., Santamaría, P.G., Guardavaccaro, D., and Pagano, M. (2007). APC/C(Cdc20) controls the ubiquitin-mediated degradation of $\mathrm{p} 21$ in prometaphase. Mol. Cell 27, 462-473.

Amir, R., Ciechanover, A., and Cohen, S. (2001). [The ubiquitin-proteasome system: the relationship between protein degradation and human diseases.] Harefuah 140, 1172-1176, 1229.

Ampatzidou, E., Irmisch, A., O'Connell, M.J., and Murray, J.M. (2006). Smc5/6 is required for repair at collapsed replication forks. Mol. Cell. Biol. 26, 9387-9401.

Andersen, P.L., Xu, F., and Xiao, W. (2008). Eukaryotic DNA damage tolerance and translesion synthesis through covalent modifications of PCNA. Cell Res. 18, 162-173.

Angers, S., Li, T., Yi, X., MacCoss, M.J., Moon, R.T., and Zheng, N. (2006). Molecular architecture and assembly of the DDB1-CUL4A ubiquitin ligase machinery. Nature 443, 590-593.

Aparicio, O.M., Weinstein, D.M., and Bell, S.P. (1997). Components and dynamics of DNA replication complexes in S. cerevisiae: redistribution of MCM proteins and Cdc45p during S phase. Cell 91, 59-69.

Araki, M., Wharton, R.P., Tang, Z., Yu, H., and Asano, M. (2003). Degradation of origin recognition complex large subunit by the anaphase-promoting complex in Drosophila. EMBO J. 22, 6115-6126. https://doi. org/10.1093/emboj/cdg573.

Araki, M., Yu, H., and Asano, M. (2005). A novel motif governs APC-dependent degradation of Drosophila ORC1 in vivo. Genes Dev. 19, 2458-2465.

Arias, E.E., and Walter, J.C. (2006). PCNA functions as a molecular platform to trigger Cdt1 destruction and prevent re-replication. Nat. Cell Biol. 8, 84-90.

Armstrong, A.A., Mohideen, F., and Lima, C.D. (2012). Recognition of SUMO-modified PCNA requires tandem receptor motifs in Srs2. Nature 483, 59-63. https://doi.org/10.1038/nature10883.

Barthelme, D., Chen, J.Z., Grabenstatter, J., Baker, T.A., and Sauer, R.T. (2014). Architecture and assembly of the archaeal Cdc $48^{*} 20 S$ proteasome. Proc. Natl. Acad. Sci. U.S.A. 111, E1687-94. https://doi.org/10.1073/ pnas. 1404823111.

Bashir, T., Dorrello, N.V., Amador, V., Guardavaccaro, D., and Pagano, M. (2004). Control of the SCF(Skp2Cks1) ubiquitin ligase by the APC/C(Cdh1) ubiquitin ligase. Nature 428, 190-193. https://doi.org/10.1038/ nature 02330 .

Beck, D.B., Burton, A., Oda, H., Ziegler-Birling, C., TorresPadilla, M.E., and Reinberg, D. (2012a). The role of PR-Set7 in replication licensing depends on Suv4-20h. Genes Dev. 26, 2580-2589. https://doi.org/10.1101/ gad.195636.112.

Beck, D.B., Oda, H., Shen, S.S., and Reinberg, D. (2012b). PR-Set7 and H4K20me1: at the crossroads of genome integrity, cell cycle, chromosome condensation, and transcription. Genes Dev. 26, 325-337. https://doi. org/10.1101/gad.177444.111.

Behrends, C., and Harper, J.W. (2011). Constructing and decoding unconventional ubiquitin chains. Nat. Struct. Mol. Biol. 18, 520-528. https://doi.org/10.1038/ nsmb.2066.

Bell, S.P. (2014). DNA Replication. Terminating the replisome. Science 346, 418-419. https://doi. org/10.1126/science.1261245.

Bell,S.P., andDutta,A.(2002).DNAreplicationin eukaryotic cells. Annu. Rev. Biochem. 71, 333-374. https://doi. org/10.1146/annurev.biochem.71.110601.135425. 
Bell, S.P., and Labib, K. (2016). Chromosome duplication in Saccharomyces cerevisiae. Genetics 203, 1027-1067. https://doi.org/10.1534/genetics.115.186452.

Bell, S.P., and Stillman, B. (1992). ATP-dependent recognition of eukaryotic origins of DNA replication by a multiprotein complex. Nature 357, 128-134. https:// doi.org/10.1038/357128a0.

Bembenek, J., and Yu, H. (2001). Regulation of the anaphase-promoting complex by the dual specificity phosphatase human Cdc14a. J. Biol. Chem. 276, 4823748242. https://doi.org/10.1074/jbc.M108126200.

Benamar, M., Guessous, F., Du, K., Corbett, P., Obeid, J., Gioeli, D., Slingluff, C.L., and Abbas, T. (2016). Inactivation of the CRL4-CDT2-SET 8/p21 ubiquitylation and degradation axis underlies the therapeutic efficacy of pevonedistat in melanoma. EBioMedicine 10, 85-100. https://doi.org/10.1016/j. ebiom.2016.06.023.

Bialik, P., and Woźniak, K. (2017). SUMO proteases as potential targets for cancer therapy. Postepy Hig. Med. Dosw. 71, 997-1004. https://doi. org/10.5604/01.3001.0010.6667.

Bienko, M., Green, C.M., Crosetto, N., Rudolf, F., Zapart, G., Coull, B., Kannouche, P., Wider, G., Peter, M., Lehmann, A.R., et al. (2005). Ubiquitin-binding domains in Y-family polymerases regulate translesion synthesis. Science 310, 1821-1824.

Blow, J.J., and Dutta, A. (2005). Preventing re-replication of chromosomal DNA. Nat. Rev. Mol. Cell Biol. 6, 476-486.

Bonne-Andrea, C., Kahli, M., Mechali, F., Lemaitre, J.M., Bossis, G., and Coux, O. (2013). SUMO2/3 modification of cyclin $\mathrm{E}$ contributes to the control of replication origin firing. Nat. Commun. 4, 1850. https:// doi.org/10.1038/ncomms2875.

Boos, D., Sanchez-Pulido, L., Rappas, M., Pearl, L.H., Oliver, A.W., Ponting, C.P., and Diffley, J.F. (2011). Regulation of DNA replication through Sld3-Dpb11 interaction is conserved from yeast to humans. Curr. Biol. 21, 1152 1157. https://doi.org/10.1016/j.cub.2011.05.057.

Bornstein, G., Bloom, J., Sitry-Shevah, D., Nakayama, K., Pagano, M., and Hershko, A. (2003). Role of the SCFSkp2 ubiquitin ligase in the degradation of p21Cip1 in S phase. J. Biol. Chem. 278, 25752-25757. https:// doi.org/10.1074/jbc.M301774200.

Bosu, D.R., and Kipreos, E.T. (2008). Cullin-RING ubiquitin ligases: global regulation and activation cycles. Cell Div. 3, 7. https://doi.org/10.1186/1747-1028-3-7.

Branzei, D. (2011). Ubiquitin family modifications and template switching. FEBS Lett. 585, 2810-2817. https://doi.org/10.1016/j.febslet.2011.04.053.

Branzei, D., Seki, M., and Enomoto, T. (2004). Rad18/ Rad5/Mms2-mediated polyubiquitination of PCNA is implicated in replication completion during replication stress. Genes Cells 9, 1031-1042.

Branzei, D., Sollier, J., Liberi, G., Zhao, X., Maeda, D., Seki, M., Enomoto, T., Ohta, K., and Foiani, M. (2006). Ubc9- and mms21-mediated sumoylation counteracts recombinogenic events at damaged replication forks. Cell 127, 509-522.

Branzei, D., Vanoli, F., and Foiani, M. (2008). SUMOylation regulates Rad18-mediated template switch. Nature 456, 915-920. https://doi.org/10.1038/nature07587.
Bruck, I., and Kaplan, D.L. (2015). The replication initiation protein Sld3/treslin orchestrates the assembly of the replication fork helicase during S phase. J. Biol. Chem. 290, 27414-27424. https://doi.org/10.1074/jbc. M115.688424.

Bruck, I., and Kaplan, D.L. (2017). The replication initiation protein Sld3/Treslin orchestrates the assembly of the replication fork helicase during $S$ phase. J. Biol. Chem. 292, 10319. https://doi.org/10.1074/jbc. A115.688424.

Bursomanno, S., Beli, P., Khan, A.M., Minocherhomji, S., Wagner, S.A., Bekker-Jensen, S., Mailand, N., Choudhary, C., Hickson, I.D., and Liu, Y. (2015). Proteome-wide analysis of SUMO2 targets in response to pathological DNA replication stress in human cells. DNA Repair 25, 84-96. https://doi.org/10.1016/j.dnarep.2014.10.011.

Cadoret, J.C., Meisch, F., Hassan-Zadeh, V., Luyten, I., Guillet, C., Duret, L., Quesneville, H., and Prioleau, M.N. (2008). Genome-wide studies highlight indirect links between human replication origins and gene regulation. Proc. Natl. Acad. Sci. U.S.A. 105, 1583715842. https://doi.org/10.1073/pnas.0805208105.

Caillat, C., and Perrakis, A. (2012). Cdt1 and geminin in DNA replication initiation. Subcell. Biochem. 62, 71-87. https://doi.org/10.1007/978-94-007-4572-8_5.

Cappell, S.D., Chung, M., Jaimovich, A., Spencer, S.L., and Meyer, T. (2016). Irreversible APC(Cdh1) inactivation underlies the point of no return for cell-cycle entry. Cell 166, 167-180. https://doi.org/10.1016/j. cell.2016.05.077.

Cardozo, T., and Pagano, M. (2004). The SCF ubiquitin ligase: insights into a molecular machine. Nat. Rev. Mol. Cell Biol. 5, 739-751. https://doi.org/10.1038/ nrm1471.

Centore, R.C., Havens, C.G., Manning, A.L., Li, J.M., Flynn, R.L., Tse, A., Jin, J., Dyson, N.J., Walter, J.C., and Zou, L. (2010). CRL4(Cdt2)-mediated destruction of the histone methyltransferase Set8 prevents premature chromatin compaction in S phase. Mol. Cell 40, 22-33. https://doi.org/10.1016/j.molcel.2010.09.015.

Chandrasekaran, S., Tan, T.X., Hall, J.R., and Cook, J.G. (2011). Stress-stimulated mitogen-activated protein kinases control the stability and activity of the Cdt1 DNA replication licensing factor. Mol. Cell. Biol. 31, 4405-4416. https://doi.org/10.1128/MCB.06163-11.

Chattopadhyay, S., and Bielinsky, A.K. (2007). Human Mcm10 regulates the catalytic subunit of DNA polymerase-alpha and prevents DNA damage during replication. Mol. Biol. Cell 18, 4085-4095.

Chen, N.P., Uddin, B., Voit, R., and Schiebel, E. (2016). Human phosphatase CDC14A is recruited to the cell leading edge to regulate cell migration and adhesion. Proc. Natl. Acad. Sci. U.S.A. 113, 990-995. https://doi. org/10.1073/pnas.1515605113.

Chen, Y.H., Choi, K., Szakal, B., Arenz, J., Duan, X., Ye, H., Branzei, D., and Zhao, X. (2009). Interplay between the Smc5/6 complex and the Mph1 helicase in recombinational repair. Proc. Natl. Acad. Sci. U.S.A. 106, 21252-21257. https://doi.org/10.1073/ pnas.0908258106.

Chen, Z., Sui, J., Zhang, F., and Zhang, C. (2015). Cullin family proteins and tumorigenesis: genetic association 
and molecular mechanisms. J. Cancer 6, 233-242. https://doi.org/10.7150/jca.11076.

Chin, J.K., Bashkirov, V.I., Heyer, W.D., and Romesberg, F.E. (2006). Esc4/Rtt107 and the control of recombination during replication. DNA Repair 5, 618-628.

Cho, W.H., Lee, Y.J., Kong, S.I., Hurwitz, J., and Lee, J.K. (2006). CDC7 kinase phosphorylates serine residues adjacent to acidic amino acids in the minichromosome maintenance 2 protein. Proc. Natl. Acad. Sci. U.S.A. 103, 11521-11526.

Choe, K.N., and Moldovan, G.L. (2017). Forging ahead through darkness: PCNA, still the principal conductor at the replication fork. Mol. Cell 65, 380-392.

Choi, K., Szakal, B., Chen, Y.H., Branzei, D., and Zhao, $X$. (2010). The Smc5/6 complex and Esc2 influence multiple replication-associated recombination processes in Saccharomyces cerevisiae. Mol. Biol. Cell 21, 23062314. https://doi.org/10.1091/mbc.E10-01-0050.

Chuang, R.Y., and Kelly, T.J. (1999). The fission yeast homologue of Orc4p binds to replication origin DNA via multiple AT-hooks. Proc. Natl. Acad. Sci. U.S.A. 96, 2656-2661.

Ciechanover, A., and Schwartz, A.L. (2002). Ubiquitinmediated degradation of cellular proteins in health and disease. Hepatology 35, 3-6.

Clijsters, L., and Wolthuis, R. (2014). PIP-box-mediated degradation prohibits re-accumulation of Cdc6 during $S$ phase. J. Cell Sci. 127, 1336-1345.

Clurman, B.E., Sheaff, R.J., Thress, K., Groudine, M., and Roberts, J.M. (1996). Turnover of cyclin E by the ubiquitin-proteasome pathway is regulated by cdk2 binding and cyclin phosphorylation. Genes Dev. 10, 1979-1990.

Collins, S.R., Miller, K.M., Maas, N.L., Roguev, A., Fillingham, J., Chu, C.S., Schuldiner, M., Gebbia, M., Recht, J., Shales, M., et al. (2007). Functional dissection of protein complexes involved in yeast chromosome biology using a genetic interaction map. Nature 446, 806-810.

Cornacchia, D., Dileep, V., Quivy, J.P., Foti, R., Tili, F., Santarella-Mellwig, R., Antony, C., Almouzni, G., Gilbert, D.M., and Buonomo, S.B. (2012). Mouse Rif1 is a key regulator of the replication-timing programme in mammalian cells. EMBO J. 31, 3678-3690. https://doi. org/10.1038/emboj.2012.214.

Craig, J.M., Earle, E., Canham, P., Wong, L.H., Anderson, M., and Choo, K.H. (2003). Analysis of mammalian proteins involved in chromatin modification reveals new metaphase centromeric proteins and distinct chromosomal distribution patterns. Hum. Mol. Genet. 12, 3109-3121. https://doi.org/10.1093/hmg/ ddg330.

Cremona, C.A., Sarangi, P., Yang, Y., Hang, L.E., Rahman, S., and Zhao, X. (2012). Extensive DNA damageinduced sumoylation contributes to replication and repair and acts in addition to the mecl checkpoint. Mol. Cell 45, 422-432. https://doi.org/10.1016/j. molcel.2011.11.028.

Crosas, B. (2014). Deubiquitinating enzyme inhibitors and their potential in cancer therapy. Curr. Cancer Drug Targets 14, 506-516
Dai, J., Chuang, R.Y., and Kelly, T.J. (2005). DNA replication origins in the Schizosaccharomyces pombe genome. Proc. Natl. Acad. Sci. U.S.A. 102, 337-342.

Dantuma, N.P., and Pfeiffer, A. (2016). Real estate in the DNA damage response: ubiquitin and SUMO ligases home in on DNA double-strand breaks. Front. Genet. 7, 58. https://doi.org/10.3389/fgene.2016.00058.

D'Arcy, P., Wang, X., and Linder, S. (2015). Deubiquitinase inhibition as a cancer therapeutic strategy. Pharmacol. Ther. 147, 32-54. https://doi.org/10.1016/j. pharmthera.2014.11.002.

Das-Bradoo, S., Ricke, R.M., and Bielinsky, A.K. (2006). Interaction between PCNA and diubiquitinated $\mathrm{Mcm} 10$ is essential for cell growth in budding yeast. Mol. Cell. Biol. 26, 4806-4817.

Davé, A., Cooley, C., Garg, M., and Bianchi, A. (2014). Protein phosphatase 1 recruitment by Rif1 regulates DNA replication origin firing by counteracting DDK activity. Cell Rep. 7, 53-61. https://doi.org/10.1016/j. celrep.2014.02.019.

de Albuquerque, C.P., Liang, J., Gaut, N.J., and Zhou, H. (2016). Molecular circuitry of the SUMO (small ubiquitin-like modifier) pathway in controlling sumoylation homeostasis and suppressing genome rearrangements.J. Biol. Chem. 291, 8825-8835. https:// doi.org/10.1074/jbc.M116.716399.

den Elzen, N., and Pines, J. (2001). Cyclin A is destroyed in prometaphase and can delay chromosome alignment and anaphase. J. Cell Biol. 153, 121-136.

Deshaies, R.J., and Joazeiro, C.A. (2009). RING domain E3 ubiquitin ligases. Annu. Rev. Biochem. 78, 399-434. https://doi.org/10.1146/annurev. biochem.78.101807.093809.

Devault, A., Vallen, E.A., Yuan, T., Green, S., Bensimon, A., and Schwob, E. (2002). Identification of Tah11/Sid2 as the ortholog of the replication licensing factor Cdt1 in Saccharomyces cerevisiae. Curr. Biol. 12, 689-694.

Dewar, J.M., and Walter, J.C. (2017). Mechanisms of DNA replication termination. Nat. Rev. Mol. Cell Biol. 18, 507-516. https://doi.org/10.1038/nrm.2017.42.

Dewar, J.M., Low, E., Mann, M., Räschle, M., and Walter, J.C. (2017). CRL2Lrr1 promotes unloading of the vertebrate replisome from chromatin during replication termination. Genes Dev. 31, 275-290. https://doi. org/10.1101/gad.291799.116.

Dhar, M.K., Sehgal, S., and Kaul, S. (2012). Structure, replication efficiency and fragility of yeast ARS elements. Res. Microbiol. 163, 243-253. https://doi. org/10.1016/j.resmic.2012.03.003.

Di Fiore, B., and Pines, J. (2007). Emil is needed to couple DNA replication with mitosis but does not regulate activation of the mitotic APC/C. J. Cell Biol. 177, 425-437.

Donzelli, M., Squatrito, M., Ganoth, D., Hershko, A., Pagano, M., and Draetta, G.F. (2002). Dual mode of degradation of Cdc25 A phosphatase. EMBO J. 21, 4875-4884.

Doulatov, S., Notta, F., Laurenti, E., and Dick, J.E. (2012). Hematopoiesis: a human perspective. Cell Stem Cell 10, 120-136. https://doi.org/10.1016/j.stem.2012.01.006.

Duan, S., Cermak, L., Pagan, J.K., Rossi, M., Martinengo, C., di Celle, P.F., Chapuy, B., Shipp, M., Chiarle, R., and Pagano, M. (2012). FBXO11 targets BCL6 for degradation and is inactivated in diffuse large 
B-cell lymphomas. Nature 481, 90-93. https://doi. org/10.1038/nature10688.

Duda, D.M., Scott, D.C., Calabrese, M.F., Zimmerman, E.S., Zheng, N., and Schulman, B.A. (2011). Structural regulation of cullin-RING ubiquitin ligase complexes. Curr. Opin. Struct. Biol. 21, 257-264. https://doi. org/10.1016/j.sbi.2011.01.003.

Dumas, L.B., Lussky, J.P., McFarland, E.J., and Shampay, J. (1982). New temperature-sensitive mutants of Saccharomyces cerevisiae affecting DNA replication. Mol. Gen. Genet. 187, 42-46.

Dungrawala, H., Rose, K.L., Bhat, K.P., Mohni, K.N., Glick, G.G., Couch, F.B., and Cortez, D. (2015). The replication checkpoint prevents two types of fork collapse without regulating replisome stability. Mol. Cell 59, 998-1010. https://doi.org/10.1016/j.molcel.2015.07.030.

Elrouby, N., and Coupland, G. (2010). Proteome-wide screens for small ubiquitin-like modifier (SUMO) substrates identify Arabidopsis proteins implicated in diverse biological processes. Proc. Natl. Acad. Sci. U.S.A. 107, 17415-17420. https://doi.org/10.1073/ pnas. 1005452107.

Fachinetti, D., Bermejo, R., Cocito, A., Minardi, S., Katou, Y., Kanoh, Y., Shirahige, K., Azvolinsky, A., Zakian, V.A., and Foiani, M. (2010). Replication termination at eukaryotic chromosomes is mediated by Top 2 and occurs at genomic loci containing pausing elements. Mol. Cell 39, 595-605. https://doi.org/10.1016/j. molcel.2010.07.024.

Fang, D., Cao, Q. and Lou, H. (2016). Sld3-MCM Interaction Facilitated by Dbf4-Dependent Kinase Defines an Essential Step in Eukaryotic DNA Replication Initiation. Front. Microbiol. 7, 885. https:// doi.org/10.3389/fmicb.2016.00885.

Frampton, J., Irmisch, A., Green, C.M., Neiss, A., Trickey, M., Ulrich, H.D., Furuya, K., Watts, F.Z., Carr, A.M., and Lehmann, A.R. (2006). Postreplication repair and PCNA modification in Schizosaccharomyces pombe. Mol. Biol. Cell 17, 2976-2985.

Fujimitsu, K., Grimaldi, M., and Yamano, H. (2016). Cyclindependent kinase 1-dependent activation of APC/C ubiquitin ligase. Science 352, 1121-1124. https://doi. org/10.1126/science.aad3925.

Fujita, M., Yamada, C., Goto, H., Yokoyama, N., Kuzushima, K., Inagaki, M., and Tsurumi, T. (1999). Cell cycle regulation of human CDC6 protein. Intracellular localization, interaction with the human mcm complex, and CDC2 kinase-mediated hyperphosphorylation. J. Biol. Chem. 274, 25927-25932.

Gali, H., Juhasz, S., Morocz, M., Hajdu, I., Fatyol, K., Szukacsov, V., Burkovics, P., and Haracska, L. (2012). Role of SUMO modification of human PCNA at stalled replication fork. Nucleic Acids Res. 40, 6049-6059. https://doi.org/10.1093/nar/gks256.

Gallego-Sánchez, A., Andrés, S., Conde, F., San-Segundo, P.A., and Bueno, A. (2012). Reversal of PCNA ubiquitylation by Ubp10 in Saccharomyces cerevisiae. PLOS Genet. 8, e1002826. https://doi.org/10.1371/ journal.pgen.1002826.

Gambus, A. (2017). Termination of eukaryotic replication forks. Adv. Exp. Med. Biol. 1042, 163-187. https://doi. org/10.1007/978-981-10-6955-0_8.
Gambus, A., Jones, R.C., Sanchez-Diaz, A., Kanemaki, M., van Deursen, F., Edmondson, R.D., and Labib, K. (2006). GINS maintains association of Cdc45 with $\mathrm{MCM}$ in replisome progression complexes at eukaryotic DNA replication forks. Nat. Cell Biol. 8, 358-366.

García-Rodríguez, N., Wong, R.P., and Ulrich, H.D. (2016). Functions of ubiquitin and SUMO in DNA replication and replication stress. Front. Genet. 7, 87. https://doi. org/10.3389/fgene.2016.00087.

Gareau, J.R., and Lima, C.D. (2010). The SUMO pathway: emerging mechanisms that shape specificity, conjugation and recognition. Nat. Rev. Mol. Cell Biol. 11, 861-871. https://doi.org/10.1038/nrm3011.

Gibbs-Seymour, I., Oka, Y., Rajendra, E., Weinert, B.T., Passmore, L.A., Patel, K.J., Olsen, J.V., Choudhary, C., Bekker-Jensen, S., and Mailand, N. (2015). UbiquitinSUMO circuitry controls activated fanconi anemia ID complex dosage in response to DNA damage. Mol. Cell 57, 150-164. https://doi.org/10.1016/j. molcel.2014.12.001.

Glickman, M.H., and Ciechanover, A. (2002). The ubiquitin-proteasome proteolytic pathway: destruction for the sake of construction. Physiol. Rev. 82, 373-428. https://doi.org/10.1152/physrev.00027.2001.

Golebiowski, F., Matic, I., Tatham, M.H., Cole, C., Yin, Y., Nakamura, A., Cox, J., Barton, G.J., Mann, M., and Hay, R.T. (2009). System-wide changes to SUMO modifications in response to heat shock. Sci. Signal. 2, ra24. https://doi.org/10.1126/scisignal.2000282.

Gregan, J., Lindner, K., Brimage, L., Franklin, R., Namdar, M., Hart, E.A., Aves, S.J., and Kearsey, S.E. (2003). Fission yeast $\mathrm{Cdc} 23 / \mathrm{Mcm} 10$ functions after prereplicative complex formation to promote $\mathrm{Cdc} 45$ chromatin binding. Mol. Biol. Cell 14, 3876-3887. https://doi.org/10.1091/mbc.e03-02-0090.

Groll, M., and Huber, R. (2003). Substrate access and processing by the $20 \mathrm{~S}$ proteasome core particle. Int. J. Biochem. Cell Biol. 35, 606-616.

Groth, A. (2009). Replicating chromatin: a tale of histones. Biochem. Cell Biol. 87, 51-63. https://doi. org/10.1139/O08-102.

Groth, A., Corpet, A., Cook, A.J., Roche, D., Bartek, J., Lukas, J., and Almouzni, G. (2007). Regulation of replication fork progression through histone supply and demand. Science 318, 1928-1931.

Guardavaccaro, D., Kudo, Y., Boulaire, J., Barchi, M., Busino, L., Donzelli, M., Margottin-Goguet, F., Jackson, P.K., Yamasaki, L., and Pagano, M. (2003). Control of meiotic and mitotic progression by the $\mathrm{F}$ box protein beta-Trcp 1 in vivo. Dev. Cell 4, 799-812.

Guo, Z., Kanjanapangka, J., Liu, N., Liu, S., Liu, C., Wu, Z., Wang, Y., Loh, T., Kowolik, C., Jamsen, J., et al. (2012). Sequential posttranslational modifications program FEN1 degradation during cell-cycle progression. Mol. Cell 47, 444-456. https://doi.org/10.1016/j. molcel.2012.05.042.

Han, J., Zhang, H., Zhang, H., Wang, Z., Zhou, H., and Zhang, Z. (2013). A Cul4 E3 ubiquitin ligase regulates histone hand-off during nucleosome assembly. Cell 155, 817-829. https://doi.org/10.1016/j.cell.2013.10.014.

Hang, L., and Zhao, X. (2016). The Rtt107 BRCT scaffold and its partner modification enzymes collaborate to 
promote replication. Nucleus 7, 346-351. https://doi. org/10.1080/19491034.2016.1201624.

Hang, L.E., Peng, J., Tan, W., Szakal, B., Menolfi, D., Sheng, Z., Lobachev, K., Branzei, D., Feng, W., and Zhao, X. (2015). Rtt107 Is a multi-functional scaffold supporting replication progression with partner SUMO and ubiquitin ligases. Mol. Cell 60, 268-279. https://doi. org/10.1016/j.molcel.2015.08.023.

Hansen, F.G., and Atlung, T. (2018). The DnaA Tale. Front. Microbiol. 9, 319. https://doi.org/10.3389/ fmicb.2018.00319.

Haracska, L., Torres-Ramos, C.A., Johnson, R.E., Prakash, S., and Prakash, L. (2004). Opposing effects of ubiquitin conjugation and SUMO modification of PCNA on replicational bypass of DNA lesions in Saccharomyces cerevisiae. Mol. Cell. Biol. 24, 4267-4274.

Harrigan, J.A., Jacq, X., Martin, N.M., and Jackson, S.P. (2018). Deubiquitylating enzymes and drug discovery: emerging opportunities. Nat. Rev. Drug Discov. 17, 57-78. https://doi.org/10.1038/nrd.2017.152.

Havens, C.G., and Walter, J.C. (2009). Docking of a specialized PIP Box onto chromatin-bound PCNA creates a degron for the ubiquitin ligase CRL4Cdt2. Mol. Cell 35, 93-104. https://doi.org/10.1016/j. molcel.2009.05.012.

Havens, C.G., and Walter, J.C. (2011). Mechanism of CRL4(Cdt2), a PCNA-dependent E3 ubiquitin ligase. Genes Dev. 25, 1568-1582. https://doi.org/10.1101/ gad.2068611.

Hayano, M., Kanoh, Y., Matsumoto, S., Renard-Guillet, C., Shirahige, K., and Masai, H. (2012). Rif1 is a global regulator of timing of replication origin firing in fission yeast. Genes Dev. 26, 137-150. https://doi. org/10.1101/gad.178491.111.

Hayashi, M., Katou, Y., Itoh, T., Tazumi, A., Tazumi, M., Yamada, Y., Takahashi, T., Nakagawa, T., Shirahige, K., and Masukata, H. (2007). Genome-wide localization of pre-RC sites and identification of replication origins in fission yeast. EMBO J. 26, 1327-1339.

He, Y.J., McCall, C.M., Hu, J., Zeng, Y., and Xiong, Y. (2006). DDB1 functions as a linker to recruit receptor WD40 proteins to CUL4-ROC1 ubiquitin ligases. Genes Dev. 20, 2949-2954.

Hedglin, M., and Benkovic, S.J. (2015). Regulation of Rad6/ Rad18 activity during DNA damage tolerance. Annu. Rev. Biophys. 44, 207-228. https://doi.org/10.1146/ annurev-biophys-060414-033841.

Hendriks, I.A., D’Souza, R.C., Yang, B., Verlaan-de Vries, M., Mann, M., and Vertegaal, A.C. (2014). Uncovering global SUMOylation signaling networks in a sitespecific manner. Nat. Struct. Mol. Biol. 21, 927-936. https://doi.org/10.1038/nsmb.2890.

Hendriks, I.A., Schimmel, J., Eifler, K., Olsen, J.V., and Vertegaal, A.C. (2015). Ubiquitin-specific protease 11 (USP11) deubiquitinates hybrid small ubiquitin-like modifier (SUMO)-ubiquitin chains to counteract RING finger protein 4 (RNF4). J. Biol. Chem. 290, 1552615537. https://doi.org/10.1074/jbc.M114.618132.

Henikoff, S. (2016). Mechanisms of nucleosome dynamics in vivo. Cold Spring Harb. Perspect. Med. 6, a026666. https://doi.org/10.1101/cshperspect.a026666.

Heo, J., Eki, R., and Abbas, T. (2016). Deregulation of F-box proteins and its consequence on cancer development, progression and metastasis. Semin. Cancer Biol. 36, 33-51. https://doi.org/10.1016/j. semcancer.2015.09.015.

Hershko, A. (2005). The ubiquitin system for protein degradation and some of its roles in the control of the cell division cycle. Cell Death Differ. 12, 1191-1197.

Hickey, C.M., Wilson, N.R., and Hochstrasser, M. (2012). Function and regulation of SUMO proteases. Nat. Rev. Mol. Cell Biol. 13, 755-766. https://doi.org/10.1038/ nrm3478.

Higa, L.A., and Zhang, H. (2007). Stealing the spotlight: CUL4-DDB1 ubiquitin ligase docks WD40-repeat proteins to destroy. Cell Div. 2, 5 .

Higa, L.A., Mihaylov, I.S., Banks, D.P., Zheng, J., and Zhang, H. (2003). Radiation-mediated proteolysis of CDT1 by CUL4-ROC1 and CSN complexes constitutes a new checkpoint. Nat. Cell Biol. 5, 1008-1015. https://doi. org/10.1038/ncb1061.

Higa, L.A., Banks, D., Wu, M., Kobayashi, R., Sun, H., and Zhang, H. (2006). L2DTL/CDT2 interacts with the CUL4/DDB1 complex and PCNA and regulates CDT1 proteolysis in response to DNA damage. Cell Cycle 5, 1675-1680.

Hiraga, S., Alvino, G.M., Chang, F., Lian, H.Y., Sridhar, A., Kubota, T., Brewer, B.J., Weinreich, M., Raghuraman, M.K., and Donaldson, A.D. (2014). Rif1 controls DNA replication by directing Protein Phosphatase 1 to reverse Cdc7-mediated phosphorylation of the MCM complex. Genes Dev. 28, 372-383. https://doi.org/10.1101/ gad.231258.113.

Hoege, C., Pfander, B., Moldovan, G.L., Pyrowolakis, G., and Jentsch, S. (2002). RAD6-dependent DNA repair is linked to modification of PCNA by ubiquitin and SUMO. Nature 419, 135-141. https://doi. org/10.1038/nature00991.

Hoeller, D., and Dikic, I. (2009). Targeting the ubiquitin system in cancer therapy. Nature $458,438-444$. https: / / doi.org/10.1038/nature07960.

Hotton, S.K., and Callis, J. (2008). Regulation of cullin RING ligases. Annu. Rev. Plant Biol. 59, 467-489. https://doi. org/10.1146/annurev.arplant.58.032806.104011.

Hua, Z., and Vierstra, R.D. (2011). The cullin-RING ubiquitin-protein ligases. Annu. Rev. Plant Biol. 62, 299-334. https://doi.org/10.1146/annurevarplant-042809-112256.

Huang, C., Cheng, J., Bawa-Khalfe, T., Yao, X., Chin, Y.E., and Yeh, E.T.H. (2016). SUMOylated ORC2 recruits a histone demethylase to regulate centromeric histone modification and genomic stability. Cell Rep. 15, 147-157.

Huang, H.L., Zheng, W.L., Zhao, R., Zhang, B., and Ma, W.L. (2010). FBXO31 is down-regulated and may function as a tumor suppressor in hepatocellular carcinoma. Oncol. Rep. 24, 715-720.

Huang, T.T., Nijman, S.M., Mirchandani, K.D., Galardy, P.J., Cohn, M.A., Haas, W., Gygi, S.P., Ploegh, H.L., Bernards, R., and D'Andrea, A.D. (2006). Regulation of monoubiquitinated PCNA by DUB autocleavage. Nat. Cell Biol. 8, 339-347.

Ilves, I., Petojevic, T., Pesavento, J.J., and Botchan, M.R. (2010). Activation of the MCM2-7 helicase by association with $\mathrm{Cdc} 45$ and GINS proteins. 
Mol. Cell 37, 247-258. https://doi.org/10.1016/j. molcel.2009.12.030.

Jalal, D., Chalissery, J., and Hassan, A.H. (2017). Genome maintenance in Saccharomyces cerevisiae: the role of SUMO and SUMO-targeted ubiquitin ligases. Nucleic Acids Res. 45, 2242-2261. https://doi.org/10.1093/ nar/gkw1369.

Jasencakova, Z., and Groth, A. (2010). Restoring chromatin after replication: how new and old histone marks come together. Semin. Cell Dev. Biol. 21, 231-237. https:// doi.org/10.1016/j.semcdb.2009.09.018.

Jaspersen, S.L., Charles, J.F., and Morgan, D.O. (1999). Inhibitory phosphorylation of the APC regulator Hct1 is controlled by the kinase $\mathrm{Cdc} 28$ and the phosphatase Cdc14. Curr. Biol. 9, 227-236.

Jiang, W., Wells, N.J., and Hunter, T. (1999). Multistep regulation of DNA replication by Cdk phosphorylation of HsCdc6. Proc. Natl. Acad. Sci. U.S.A. 96, 6193-6198.

Jin, J., Arias, E.E., Chen, J., Harper, J.W., and Walter, J.C. (2006). A family of diverse Cul4-Ddb1-interacting proteins includes $\mathrm{Cdt} 2$, which is required for $S$ phase destruction of the replication factor Cdt1. Mol. Cell 23, 709-721.

Johansson, P., Jeffery, J., Al-Ejeh, F., Schulz, R.B., Callen, D.F., Kumar, R., and Khanna, K.K. (2014). SCFFBXO31 E3 ligase targets DNA replication factor Cdt1 for proteolysis in the G2 phase of cell cycle to prevent re-replication. J. Biol. Chem. 289, 18514-18525. https://doi.org/10.1074/jbc.M114.559930.

Johnson, E.S. (2004). Protein modification by SUMO. Annu. Rev. Biochem. 73, 355-382. https://doi. org/10.1146/annurev.biochem.73.011303.074118.

Jørgensen, S., Eskildsen, M., Fugger, K., Hansen, L., Larsen, M.S., Kousholt, A.N., Syljuåsen, R.G., Trelle, M.B., Jensen, O.N., Helin, K., et al. (2011). SET8 is degraded via PCNA-coupled CRL4(CDT2) ubiquitylation in S phase and after UV irradiation. J. Cell Biol. 192, 43-54. https://doi.org/10.1083/jcb.201009076.

Jørgensen, S., Schotta, G., and Sørensen, C.S. (2013). Histone H4 lysine 20 methylation: key player in epigenetic regulation of genomic integrity. Nucleic Acids Res. 41, 2797-2806. https://doi.org/10.1093/ nar/gkt012.

Jung, Y.S., Liu, G., and Chen, X. (2010). Pirh2 E3 ubiquitin ligase targets DNA polymerase eta for $20 \mathrm{~S}$ proteasomal degradation. Mol. Cell. Biol. 30, 1041-1048. https:// doi.org/10.1128/MCB.01198-09.

Jung, Y.S., Hakem, A., Hakem, R., and Chen, X. (2011). Pirh2 E3 ubiquitin ligase monoubiquitinates DNA polymerase eta to suppress translesion DNA synthesis. Mol. Cell. Biol. 31, 3997-4006. https://doi. org/10.1128/MCB.05808-11.

Jung, Y.S., Qian, Y., and Chen, X. (2012). DNA polymerase eta is targeted by $\mathrm{Mdm} 2$ for polyubiquitination and proteasomal degradation in response to ultraviolet irradiation. DNA Repair 11, 177-184. https://doi. org/10.1016/j.dnarep.2011.10.017.

Kaguni,J.M. (2011). Replication initiation at the Escherichia coli chromosomal origin. Curr. Opin. Chem. Biol. 15, 606-613.

Kaiser, B.K., Zimmerman, Z.A., Charbonneau, H., and Jackson, P.K. (2002). Disruption of centrosome structure, chromosome segregation, and cytokinesis by misexpression of human Cdc14A phosphatase. Mol. Biol. Cell 13, 2289-2300. https://doi.org/10.1091/ mbc.01-11-0535.

Kang, Y.H., Galal, W.C., Farina, A., Tappin, I., and Hurwitz, J. (2012). Properties of the human Cdc45/Mcm2-7/ GINS helicase complex and its action with DNA polymerase epsilon in rolling circle DNA synthesis. Proc. Natl. Acad. Sci. U.S.A. 109, 6042-6047. https:// doi.org/10.1073/pnas.1203734109.

Kanke, M., Kodama, Y., Takahashi, T.S., Nakagawa, T., and Masukata, H. (2012). Mcm10 plays an essential role in origin DNA unwinding after loading of the CMG components. EMBO J. 31, 2182-2194. https://doi. org/10.1038/emboj.2012.68.

Karnani, N., Taylor, C.M., Malhotra, A., and Dutta, A. (2010). Genomic study of replication initiation in human chromosomes reveals the influence of transcription regulation and chromatin structure on origin selection. Mol. Biol. Cell 21, 393-404. https://doi.org/10.1091/ mbc.E09-08-0707.

Kashiwaba, S., Kanao, R., Masuda, Y., Kusumoto-Matsuo, R., Hanaoka, F., and Masutani, C. (2015). USP7 is a suppressor of PCNA ubiquitination and oxidativestress-induced mutagenesis in human cells. Cell Rep. 13, 2072-2080. https://doi.org/10.1016/j. celrep.2015.11.014.

Katayama, T. (2017). Initiation of DNA replication at the chromosomal origin of E. coli, oriC. Adv. Exp. Med. Biol. 1042, 79-98. https://doi.org/10.1007/978-98110-6955-0_4.

Kaur, M., Khan, M.M., Kar, A., Sharma, A., and Saxena, S. (2012). CRL4-DDB1-VPRBP ubiquitin ligase mediates the stress triggered proteolysis of Mcm 10. Nucleic Acids Res. 40, 7332-7346. https://doi.org/10.1093/nar/ gks366.

Kim, Y., Starostina, N.G., and Kipreos, E.T. (2008). The CRL4Cdt2 ubiquitin ligase targets the degradation of p21Cip1 to control replication licensing. Genes Dev. 22, 2507-2519. https://doi.org/10.1101/gad.1703708.

Kipreos, E.T., and Pagano, M. (2000). The F-box protein family. Genome biology 1, REVIEWS3002.

Koepp, D.M., Schaefer, L.K., Ye, X., Keyomarsi, K., Chu, C., Harper, J.W., and Elledge, S.J. (2001). Phosphorylationdependent ubiquitination of cyclin E by the SCFFbw7 ubiquitin ligase. Science 294, 173-177. https://doi. org/10.1126/science.1065203.

Komander, D., Clague, M.J., and Urbé, S. (2009). Breaking the chains: structure and function of the deubiquitinases. Nat. Rev. Mol. Cell Biol. 10, 550-563. https://doi. org/10.1038/nrm2731.

Kornitzer, D., and Ciechanover, A. (2000). Modes of regulation of ubiquitin-mediated protein degradation. J. Cell. Physiol. 182, 1-11.

Kumagai, A., Shevchenko, A., Shevchenko, A., and Dunphy, W.G. (2010). Treslin collaborates with TopBP1 in triggering the initiation of DNA replication. Cell 140, 349-359. https://doi.org/10.1016/j.cell.2009.12.049.

Kumagai, A., Shevchenko, A., Shevchenko, A., and Dunphy, W.G. (2011). Direct regulation of Treslin by cyclindependent kinase is essential for the onset of DNA replication. J. Cell Biol. 193, 995-1007. https://doi. org/10.1083/jcb.201102003. 
Kumar, A., and Zhang, K.Y. (2015). Advances in the development of SUMO specific protease (SENP) inhibitors. Comput. Struct. Biotechnol. J. 13, 204-211. https://doi.org/10.1016/j.csbj.2015.03.001.

Kumar, C., and Remus, D. (2016). Eukaryotic replication origins: strength in flexibility. Nucleus 7, 292-300. https://doi.org/10.1080/19491034.2016.1187353.

Labib, K., and Hodgson, B. (2007). Replication fork barriers: pausing for a break or stalling for time? EMBO Rep. 8, 346-353.

Lamoliatte, F., Caron, D., Durette, C., Mahrouche, L., Maroui, M.A., Caron-Lizotte, O., Bonneil, E., ChelbiAlix, M.K., and Thibault, P. (2014). Large-scale analysis of lysine SUMOylation by SUMO remnant immunoaffinity profiling. Nat. Commun. 5, 5409. https://doi.org/10.1038/ncomms6409.

Leach, C.A., and Michael, W.M. (2005). Ubiquitin/SUMO modification of PCNA promotes replication fork progression in Xenopus laevis egg extracts. J. Cell Biol. 171, 947-954.

Lecona, E., Rodriguez-Acebes, S., Specks, J., LopezContreras, A.J., Ruppen, I., Murga, M., Muñoz, J., Mendez, J., and Fernandez-Capetillo, O. (2016). USP7 is a SUMO deubiquitinase essential for DNA replication. Nat. Struct. Mol. Biol. 23, 270-277. https:// doi.org/10.1038/nsmb.3185.

Lee, E.K., and Diehl, J.A. (2014). SCFs in the new millennium. Oncogene 33, 2011-2018. https://doi. org/10.1038/onc.2013.144.

Lee, J.K., Seo, Y.S., and Hurwitz, J. (2003). The Cdc23 $(\mathrm{Mcm} 10)$ protein is required for the phosphorylation of minichromosome maintenance complex by the Dfp1Hsk1 kinase. Proc. Natl. Acad. Sci. U.S.A. 100, 23342339. https://doi.org/10.1073/pnas.0237384100.

Lee, K.Y., Bang, S.W., Yoon, S.W., Lee, S.H., Yoon, J.B., and Hwang, D.S. (2012). Phosphorylation of ORC2 protein dissociates origin recognition complex from chromatin and replication origins. J. Biol. Chem. 287, 1189111898. https://doi.org/10.1074/jbc.M111.338467.

Lee, M.T., and Bachant, J. (2009). SUMO modification of DNA topoisomerase II: trying to get a CENse of it all. DNA Repair 8, 557-568. https://doi.org/10.1016/j. dnarep.2009.01.004.

Lei, H., Shan, H., and Wu, Y. (2017). Targeting deubiquitinating enzymes in cancer stem cells. Cancer Cell Int. 17, 101. https://doi.org/10.1186/s12935-0170472-0.

Leman, A.R., and Noguchi, E. (2013). The replication fork: understanding the eukaryotic replication machinery and the challenges to genome duplication. Genes 4, 1-32. https://doi.org/10.3390/genes4010001.

Lengronne, A., and Pasero, P. (2014). Closing the MCM cycle at replication termination sites. EMBO Rep. 15, 1226-1227. https://doi.org/10.15252/ embr.201439774.

Li, H., and Stillman, B. (2012). The origin recognition complex: a biochemical and structural view. Subcell. Biochem. 62, 37-58. https://doi.org/10.1007/978-94007-4572-8 3 .

Li, M., Pokharel, S., Wang, J.T., Xu, X., and Liu, Y. (2015). RECQ5-dependent SUMOylation of DNA topoisomerase I prevents transcription-associated genome instability. Nat. Commun. 6, 6720. https://doi. org/10.1038/ncomms7720.

Li, S.J., and Hochstrasser, M. (1999). A new protease required for cell-cycle progression in yeast. Nature 398, 246-251. https://doi.org/10.1038/18457.

Li, W., Bengtson, M.H., Ulbrich, A., Matsuda, A., Reddy, V.A., Orth, A., Chanda, S.K., Batalov, S., and Joazeiro, C.A. (2008). Genome-wide and functional annotation of human E3 ubiquitin ligases identifies MULAN, a mitochondrial E3 that regulates the organelle's dynamics and signaling. Plos One 3, e1487.

Li, X., Zhao, Q. Liao, R., Sun, P., and Wu, X. (2003). The SCF(Skp2) ubiquitin ligase complex interacts with the human replication licensing factor Cdt1 and regulates Cdt1 degradation. J. Biol. Chem. 278, 30854-30858. https://doi.org/10.1074/jbc.C300251200.

Lin, J.R., Zeman, M.K., Chen, J.Y., Yee, M.C., and Cimprich, K.A. (2011).SHPRH and HLTF act in a damage-specific manner to coordinate different forms of postreplication repair and prevent mutagenesis. Mol. Cell 42, 237-249. https://doi.org/10.1016/j.molcel.2011.02.026.

Lipkowitz, S., and Weissman, A.M. (2011). RINGs of good and evil: RING finger ubiquitin ligases at the crossroads of tumour suppression and oncogenesis. Nat. Rev. Cancer 11, 629-643. https://doi.org/10.1038/ nrc3120.

Liu, E., Li, X., Yan, F., Zhao, Q. and Wu, X. (2004). Cyclindependent kinases phosphorylate human $\mathrm{Cdt1}$ and induce its degradation. J. Biol. Chem. 279, 17283-17288. https://doi.org/10.1074/jbc.C300549200.

Liu, G., and Warbrick, E. (2006). The p66 and p12 subunits of DNA polymerase delta are modified by ubiquitin and ubiquitin-like proteins. Biochem. Biophys. Res. Commun. 349, 360-366.

Lopez-Contreras, A.J., Ruppen, I., Nieto-Soler, M., Murga, M., Rodriguez-Acebes, S., Remeseiro, S., Rodrigo-Perez, S., Rojas, A.M., Mendez, J., Muñoz, J., et al. (2013). A proteomic characterization of factors enriched at nascent DNA molecules. Cell Rep. 3, 1105-1116. https://doi. org/10.1016/j.celrep.2013.03.009.

Lovejoy, C.A., Lock, K., Yenamandra, A., and Cortez, D. (2006). DDB1 maintains genome integrity through regulation of Cdt1. Mol. Cell. Biol. 26, 7977-7990.

Lydeard, J.R., Schulman, B.A., and Harper, J.W. (2013). Building and remodelling Cullin-RING E3 ubiquitin ligases. EMBO Rep. 14, 1050-1061. https://doi. org/10.1038/embor.2013.173.

Ma, L., Aslanian, A., Sun, H., Jin, M., Shi, Y., Yates, J.R., and Hunter, T. (2014). Identification of small ubiquitinlike modifier substrates with diverse functions using the Xenopus egg extract system. Mol. Cell Proteomics 13, 1659-1675. https://doi.org/10.1074/mcp. M113.035626.

Machida, Y.J., and Dutta, A. (2007). The APC/C inhibitor, Emil, is essential for prevention of rereplication. Genes Dev. 21, 184-194.

Machida, Y.J., Hamlin, J.L., and Dutta, A. (2005). Right place, right time, and only once: replication initiation in metazoans. Cell 123, 13-24.

Mailand, N., and Diffley, J.F. (2005). CDKs promote DNA replication origin licensing in human cells by protecting Cdc6 from APC/C-dependent proteolysis. Cell 122, 915-926. 
Maric, M., Maculins, T., De Piccoli, G., and Labib, K. (2014). Cdc48 and a ubiquitin ligase drive disassembly of the CMG helicase at the end of DNA replication. Science 346, 1253596. https://doi.org/10.1126/ science. 1253596.

Masai, H., Taniyama, C., Ogino, K., Matsui, E., Kakusho, N., Matsumoto, S., Kim, J.M., Ishii, A., Tanaka, T., Kobayashi, T., et al. (2006). Phosphorylation of MCM4 by $\mathrm{Cdc} 7$ kinase facilitates its interaction with $\mathrm{Cdc} 45$ on the chromatin. J. Biol. Chem. 281, 39249-39261.

Masai, H., Matsumoto, S., You, Z., Yoshizawa-Sugata, N., and Oda, M. (2010). Eukaryotic chromosome DNA replication: where, when, and how? Annu. Rev. Biochem. 79, 89-130. https://doi.org/10.1146/ annurev.biochem.052308.103205.

Maser, R.S., Choudhury, B., Campbell, P.J., Feng, B., Wong, K.K., Protopopov, A., O’Neil, J., Gutierrez, A., Ivanova, E., Perna, I., et al. (2007). Chromosomally unstable mouse tumours have genomic alterations similar to diverse human cancers. Nature 447, 966-971.

Mattarocci, S., Shyian, M., Lemmens, L., Damay, P., Altintas, D.M., Shi, T., Bartholomew, C.R., Thomä, N.H., Hardy, C.F., and Shore, D. (2014). Rif1 controls DNA replication timing in yeast through the PP1 phosphatase Glc7. Cell Rep. 7, 62-69. https://doi.org/10.1016/j. celrep.2014.03.010.

McGarry, T.J., and Kirschner, M.W. (1998). Geminin, an inhibitor of DNA replication, is degraded during mitosis. Cell 93, 1043-1053.

McIntyre, J., and Woodgate, R. (2015). Regulation of translesion DNA synthesis: Posttranslational modification of lysine residues in key proteins. DNA Repair 29, 166-179. https://doi.org/10.1016/j. dnarep.2015.02.011.

Méndez, J., Zou-Yang, X.H., Kim, S.Y., Hidaka, M., Tansey, W.P., and Stillman, B. (2002). Human origin recognition complex large subunit is degraded by ubiquitin-mediated proteolysis after initiation of DNA replication. Mol. Cell 9, 481-491.

Merchant, A.M., Kawasaki, Y., Chen, Y., Lei, M., and Tye, B.K. (1997). A lesion in the DNA replication initiation factor $\mathrm{Mcm} 10$ induces pausing of elongation forks through chromosomal replication origins in Saccharomyces cerevisiae. Mol. Cell. Biol. 17, 3261-3271.

Michishita, M., Morimoto, A., Ishii, T., Komori, H., Shiomi, Y., Higuchi, Y., and Nishitani, H. (2011). Positively charged residues located downstream of PIP box, together with TD amino acids within PIP box, are important for CRL4(Cdt2) -mediated proteolysis. Genes Cells 16, 12-22. https://doi.org/10.1111/ j.1365-2443.2010.01464.x.

Mocciaro, A., Berdougo, E., Zeng, K., Black, E., Vagnarelli, P., Earnshaw, W., Gillespie, D., Jallepalli, P., and Schiebel, E. (2010). Vertebrate cells genetically deficient for Cdc14A or Cdc14B retain DNA damage checkpoint proficiency but are impaired in DNA repair. J. Cell Biol. 189, 631639. https://doi.org/10.1083/jcb.200910057.

Moldovan, G.L., and D’Andrea, A.D. (2011). DNA damage discrimination at stalled replication forks by the Rads homologs HLTF and SHPRH. Mol. Cell 42, 141-143. https://doi.org/10.1016/j.molcel.2011.03.018.

Montagnoli, A., Valsasina, B., Brotherton, D., Troiani, S., Rainoldi, S., Tenca, P., Molinari, A., and Santocanale,
C. (2006). Identification of $\mathrm{Mcm} 2$ phosphorylation sites by S-phase-regulating kinases. J. Biol. Chem. 281, 10281-10290.

Moreno, S.P., Bailey, R., Campion, N., Herron, S., and Gambus, A. (2014). Polyubiquitylation drives replisome disassembly at the termination of DNA replication. Science 346, 477-481. https://doi.org/10.1126/ science. 1253585

Morohashi, H., Maculins, T., and Labib, K. (2009). The amino-terminal TPR domain of Dia2 tethers SCF(Dia2) to the replisome progression complex. Curr. Biol. 19, 1943-1949. https://doi.org/10.1016/j. cub.2009.09.062.

Motegi, A., Liaw, H.J., Lee, K.Y., Roest, H.P., Maas, A., Wu, X., Moinova, H., Markowitz, S.D., Ding, H., Hoeijmakers, J.H., et al. (2008). Polyubiquitination of proliferating cell nuclear antigen by HLTF and SHPRH prevents genomic instability from stalled replication forks. Proc. Natl. Acad. Sci. U.S.A. 105, 12411-12416. https://doi.org/10.1073/pnas.0805685105.

Moyer, S.E., Lewis, P.W., and Botchan, M.R. (2006). Isolation of the $\mathrm{Cdc} 45 / \mathrm{Mcm} 2-7 / \mathrm{GINS}$ (CMG) complex, a candidate for the eukaryotic DNA replication fork helicase. Proc. Natl. Acad. Sci. U.S.A. 103, 1023610241. https://doi.org/10.1073/pnas.0602400103.

Mukhopadhyay, D., and Dasso, M. (2007). Modification in reverse: the SUMO proteases. Trends Biochem. Sci. 32, 286-295.

Muramatsu, S., Hirai, K., Tak, Y.S., Kamimura, Y., and Araki, H. (2010). CDK-dependent complex formation between replication proteins Dpb11, Sld2, Pol (epsilon\}, and GINS in budding yeast. Genes Dev. 24, 602-612. https://doi.org/10.1101/gad.1883410.

Nakayama, K.I., and Nakayama, K. (2005). Regulation of the cell cycle by SCF-type ubiquitin ligases. Semin. Cell Dev. Biol. 16, 323-333.

Narbonne-Reveau, K., Senger, S., Pal, M., Herr, A., Richardson, H.E., Asano, M., Deak, P., and Lilly, M.A. (2008). APC/CFzr/Cdh1 promotes cell cycle progression during the Drosophila endocycle. Development 135, 1451-1461. https://doi. org/10.1242/dev.016295.

Nishioka, K., Rice, J.C., Sarma, K., Erdjument-Bromage, H., Werner, J., Wang, Y., Chuikov, S., Valenzuela, P., Tempst, P., Steward, R., et al. (2002). PR-Set7 is a nucleosomespecific methyltransferase that modifies lysine 20 of histone $\mathrm{H} 4$ and is associated with silent chromatin. Mol. Cell 9, 1201-1213.

Nishitani, H., Sugimoto, N., Roukos, V., Nakanishi, Y., Saijo, M., Obuse, C., Tsurimoto, T., Nakayama, K.I., Nakayama, K., Fujita, M., et al. (2006). Two E3 ubiquitin ligases, SCF-Skp2 and DDB1-Cul4, target human Cdt1 for proteolysis. EMBO J. 25, 1126-1136.

Nishitani, H., Shiomi, Y., Iida, H., Michishita, M., Takami, T., and Tsurimoto, T. (2008). CDK inhibitor p21 is degraded by a proliferating cell nuclear antigen-coupled Cul4-DDB1Cdt2 pathway during S phase and after UV irradiation. J. Biol. Chem. 283, 29045-29052. https:// doi.org/10.1074/jbc.M806045200.

Oda, H., Hübner, M.R., Beck, D.B., Vermeulen, M., Hurwitz, J., Spector, D.L., and Reinberg, D. (2010). Regulation of the histone $\mathrm{H} 4$ monomethylase PR-Set7 by CRL4(Cdt2)-mediated PCNA-dependent degradation 
during DNA damage. Mol. Cell 40, 364-376. https:// doi.org/10.1016/j.molcel.2010.10.011.

Ohouo, P.Y., Bastos de Oliveira, F.M., Almeida, B.S., and Smolka, M.B. (2010). DNA damage signaling recruits the Rtt107-Slx4 scaffolds via Dpb11 to mediate replication stress response. Mol. Cell 39, 300-306. https://doi.org/10.1016/j.molcel.2010.06.019.

Pacek, M., Tutter, A.V., Kubota, Y., Takisawa, H., and Walter, J.C. (2006). Localization of MCM2-7, Cdc45, and GINS to the site of DNA unwinding during eukaryotic DNA replication. Mol. Cell 21, 581-587.

Papouli, E., Chen, S., Davies, A.A., Huttner, D., Krejci, L., Sung, P., and Ulrich, H.D. (2005). Crosstalk between SUMO and ubiquitin on PCNA is mediated by recruitment of the helicase Srs2p. Mol. Cell 19, 123-133.

Park, J.M., Yang, S.W., Yu, K.R., Ka, S.H., Lee, S.W., Seol, J.H., Jeon, Y.J., and Chung, C.H. (2014). Modification of PCNA by ISG15 plays a crucial role in termination of error-prone translesion DNA synthesis. Mol. Cell 54, 626-638. https://doi.org/10.1016/j. molcel.2014.03.031.

Parnas, O., Zipin-Roitman, A., Pfander, B., Liefshitz, B., Mazor, Y., Ben-Aroya, S., Jentsch, S., and Kupiec, M. (2010). Elg1, an alternative subunit of the RFC clamp loader, preferentially interacts with SUMOylated PCNA. EMBO J. 29, 2611-2622. https://doi.org/10.1038/ emboj.2010.128.

Petersen, B.O., Lukas, J., Sørensen, C.S., Bartek, J., and Helin, K. (1999). Phosphorylation of mammalian CDC6 by cyclin $\mathrm{A} / \mathrm{CDK} 2$ regulates its subcellular localization. EMBO J. 18, 396-410. https://doi.org/10.1093/ emboj/18.2.396.

Petersen, B.O., Wagener, C., Marinoni, F., Kramer, E.R., Melixetian, M., Lazzerini Denchi, E., Gieffers, C., Matteucci, C., Peters, J.M., and Helin, K. (2000). Cell cycle- and cell growth-regulated proteolysis of mammalian CDC6 is dependent on APC-CDH1. Genes Dev. 14, 2330-2343.

Petroski, M.D., and Deshaies, R.J. (2005). Function and regulation of cullin-RING ubiquitin ligases. Nat. Rev. Mol. Cell Biol. 6, 9-20.

Pfander, B., Moldovan, G.L., Sacher, M., Hoege, C., and Jentsch, S. (2005). SUMO-modified PCNA recruits Srs2 to prevent recombination during $S$ phase. Nature 436, 428-433.

Pfleger, C.M., and Kirschner, M.W. (2000). The KEN box: an APC recognition signal distinct from the $\mathrm{D}$ box targeted by Cdh1. Genes Dev. 14, 655-665.

Pfleger, C.M., Lee, E., and Kirschner, M.W. (2001). Substrate recognition by the Cdc20 and Cdh1 components of the anaphase-promoting complex. Genes Dev. 15, 23962407. https://doi.org/10.1101/gad.918201.

Pfoh, R., Lacdao, I.K., and Saridakis, V. (2015). Deubiquitinases and the new therapeutic opportunities offered to cancer. Endocr. Relat. Cancer 22, T35-54. https://doi.org/10.1530/ERC-14-0516.

Pines, J. (2006). Mitosis: a matter of getting rid of the right protein at the right time. Trends Cell Biol. 16, 55-63.

Plachta, M., Halas, A., McIntyre, J., and Sledziewska-Gojska, E. (2015). The steady-state level and stability of TLS polymerase eta are cell cycle dependent in the yeast S. cerevisiae. DNA Repair 29, 147-153. https://doi. org/10.1016/j.dnarep.2015.02.015.
Plosky, B.S., Vidal, A.E., Fernández de Henestrosa, A.R., McLenigan, M.P., McDonald, J.P., Mead, S., and Woodgate, R. (2006). Controlling the subcellular localization of DNA polymerases iota and eta via interactions with ubiquitin. EMBO J. 25, 2847-2855.

Prakash, L. (1981). Characterization of postreplication repair in Saccharomyces cerevisiae and effects of rad6, $\operatorname{rad} 18$, rev3 and rad52 mutations. Mol. Gen. Genet. 184, 471-478.

Prasanth, S.G., Prasanth, K.V., Siddiqui, K., Spector, D.L., and Stillman, B. (2004). Human Orc2 localizes to centrosomes, centromeres and heterochromatin during chromosome inheritance. EMBO J. 23, 2651-2663. https://doi.org/10.1038/sj.emboj.7600255.

Qian, J., Pentz, K., Zhu, Q. Wang, Q. He, J., Srivastava, A.K., and Wani, A.A. (2015). USP7 modulates UV-induced PCNA monoubiquitination by regulating DNA polymerase eta stability. Oncogene 34, 4791-4796. https://doi.org/10.1038/onc.2014.394.

Qing, P., Han, L., Bin, L., Yan, L., and Ping, W.X. (2011). USP7 regulates the stability and function of HLTF through deubiquitination. J. Cell. Biochem. 112, 38563862. https://doi.org/10.1002/jcb.23317.

Ragland, R.L., Patel, S., Rivard, R.S., Smith, K., Peters, A.A., Bielinsky, A.K., and Brown, E.J. (2013). RNF4 and PLK1 are required for replication fork collapse in ATRdeficient cells. Genes Dev. 27, 2259-2273. https://doi. org/10.1101/gad.223180.113.

Rahal, R., and Amon, A. (2008). Mitotic CDKs control the metaphase-anaphase transition and trigger spindle elongation. Genes Dev. 22, 1534-1548. https://doi. org/10.1101/gad.1638308.

Reimann, J.D., Freed, E., Hsu, J.Y., Kramer, E.R., Peters, J.M., and Jackson, P.K. (2001). Emil is a mitotic regulator that interacts with $\mathrm{Cdc} 20$ and inhibits the anaphase promoting complex. Cell 105, 645-655.

Renard-Guillet, C., Kanoh, Y., Shirahige, K., and Masai, H. (2014). Temporal and spatial regulation of eukaryotic DNA replication: from regulated initiation to genomescale timing program. Semin. Cell Dev. Biol. 30, 110120. https://doi.org/10.1016/j.semcdb.2014.04.014.

Renaudin, X., Koch Lerner, L., Menck, C.F., and Rosselli, F. (2016). The ubiquitin family meets the Fanconi anemia proteins. Mutat. Res. Rev. Mutat. Res. 769, 36-46. https://doi.org/10.1016/j.mrrev.2016.06.004.

Reyes-Turcu, F.E., Ventii, K.H., and Wilkinson, K.D. (2009). Regulation and cellular roles of ubiquitinspecific deubiquitinating enzymes. Annu. Rev. Biochem. 78, 363-397. https://doi.org/10.1146/annurev. biochem.78.082307.091526.

Ricke, R.M., and Bielinsky, A.K. (2004). Mcm10 regulates the stability and chromatin association of DNA polymerase-alpha. Mol. Cell 16, 173-185.

Rizzardi, L.F., Coleman, K.E., Varma, D., Matson, J.P., Oh, S., and Cook, J.G. (2015). CDK1-dependent inhibition of the E3 ubiquitin ligase CRL4CDT2 ensures robust transition from S Phase to Mitosis. J. Biol. Chem. 290, 556-567. https://doi.org/10.1074/jbc.M114.614701.

Robbins, J.A., and Cross, F.R. (2010). Regulated degradation of the APC coactivator Cdc20. Cell Div. 5, 23. https://doi.org/10.1186/1747-1028-5-23.

Roberts, T.M., Kobor, M.S., Bastin-Shanower, S.A., Ii, M., Horte, S.A., Gin, J.W., Emili, A., Rine, J., Brill, S.J., 
and Brown, G.W. (2006). Slx4 regulates DNA damage checkpoint-dependent phosphorylation of the BRCT domain protein Rtt107/Esc4. Mol. Biol. Cell 17, 539-548.

Romani, B., Shaykh Baygloo, N., Aghasadeghi, M.R., and Allahbakhshi, E. (2015). HIV-1 Vpr protein enhances proteasomal degradation of MCM10 DNA replication factor through the Cul4-DDB1[VprBP] E3 ubiquitin ligase to induce G2/M cell cycle arrest. J. Biol. Chem. 290, 17380-17389. https://doi.org/10.1074/jbc. M115.641522.

Roseaulin, L.C., Noguchi, C., Martinez, E., Ziegler, M.A., Toda, T., and Noguchi, E. (2013). Coordinated degradation of replisome components ensures genome stability upon replication stress in the absence of the replication fork protection complex. PLOS Genet. 9, e1003213. https://doi.org/10.1371/journal. pgen.1003213.

Rudra, S., and Skibbens, R.V. (2013). Cohesin codes interpreting chromatin architecture and the many facets of cohesin function. J. Cell Sci. 126, 31-41.

Saha, P., Chen, J., Thome, K.C., Lawlis, S.J., Hou, Z.H., Hendricks, M., Parvin, J.D., and Dutta, A. (1998). Human CDC6/Cdc18 associates with Orc1 and cyclincdk and is selectively eliminated from the nucleus at the onset of S phase. Mol. Cell. Biol. 18, 2758-2767.

Sansam, C.L., Shepard, J.L., Lai, K., Ianari, A., Danielian, P.S., Amsterdam, A., Hopkins, N., and Lees, J.A. (2006). $\mathrm{DTL} / \mathrm{CDT} 2$ is essential for both CDT1 regulation and the early G2/M checkpoint. Genes Dev. 20, 3117-3129.

Sarangi, P., and Zhao, X. (2015). SUMO-mediated regulation of DNA damage repair and responses. Trends Biochem. Sci. 40, 233-242. https://doi.org/10.1016/j. tibs.2015.02.006.

Sarikas, A., Hartmann, T., and Pan, Z.Q. (2011). The cullin protein family. Genome Biol. 12, 220. https://doi. org/10.1186/gb-2011-12-4-220.

Schaarschmidt, D., Baltin, J., Stehle, I.M., Lipps, H.J., and Knippers, R. (2004). An episomal mammalian replicon: sequence-independent binding of the origin recognition complex. EMBO J. 23, 191-201. https:// doi.org/10.1038/sj.emboj.7600029.

Schimmel, J., Eifler, K., Sigurðsson, J.O., Cuijpers, S.A., Hendriks, I.A., Verlaan-de Vries, M., Kelstrup, C.D., Francavilla, C., Medema, R.H., Olsen, J.V., et al. (2014). Uncovering SUMOylation dynamics during cell-cycle progression reveals FoxM1 as a key mitotic SUMO target protein. Mol. Cell 53, 1053-1066. https://doi. org/10.1016/j.molcel.2014.02.001.

Schotta, G., Sengupta, R., Kubicek, S., Malin, S., Kauer, M., Callén, E., Celeste, A., Pagani, M., Opravil, S., De La Rosa-Velazquez, I.A., et al. (2008). A chromatin-wide transition to $\mathrm{H} 4 \mathrm{~K} 20$ monomethylation impairs genome integrity and programmed DNA rearrangements in the mouse. Genes Dev. 22, 2048-2061. https://doi. org/10.1101/gad.476008.

Schulz, S., Chachami, G., Kozaczkiewicz, L., Winter, U., Stankovic-Valentin, N., Haas, P., Hofmann, K., Urlaub, H., Ovaa, H., Wittbrodt, J., et al. (2012). Ubiquitinspecific protease-like 1 (USPL1) is a SUMO isopeptidase with essential, non-catalytic functions. EMBO Rep. 13, 930-938. https://doi.org/10.1038/embor.2012.125.
Schwartz, A.L., and Ciechanover, A. (2009). Targeting proteins for destruction by the ubiquitin system: implications for human pathobiology. Annu. Rev. Pharmacol. Toxicol. 49, 73-96. https://doi. org/10.1146/annurev.pharmtox.051208.165340.

Schwertman, P., Bekker-Jensen, S., and Mailand, N. (2016). Regulation of DNA double-strand break repair by ubiquitin and ubiquitin-like modifiers. Nat. Rev. Mol. Cell Biol. 17, 379-394. https://doi.org/10.1038/ nrm.2016.58

Segurado, M., de Luis, A., and Antequera, F. (2003). Genome-wide distribution of DNA replication origins at A+T-rich islands in Schizosaccharomyces pombe. EMBO Rep. 4, 1048-1053. https://doi.org/10.1038/ sj.embor.embor 7400008 .

Senga, T., Sivaprasad, U., Zhu, W., Park, J.H., Arias, E.E., Walter, J.C., and Dutta, A. (2006). PCNA is a cofactor for Cdt1 degradation by CUL4/DDB1-mediated $\mathrm{N}$-terminal ubiquitination. J. Biol. Chem. 281, 62466252.

Sequeira-Mendes, J., Díaz-Uriarte, R., Apedaile, A., Huntley, D., Brockdorff, N., and Gómez, M. (2009). Transcription initiation activity sets replication origin efficiency in mammalian cells. PLOS Genet. 5, e1000446. https:// doi.org/10.1371/journal.pgen.1000446.

Shibutani, S.T., de la Cruz, A.F., Tran, V., Turbyfill, W.J., Reis, T., Edgar, B.A., and Duronio, R.J. (2008). Intrinsic negative cell cycle regulation provided by PIP box- and Cul4Cdt2-mediated destruction of E2f1 during $S$ phase. Dev. Cell 15, 890-900. https://doi.org/10.1016/j. devcel.2008.10.003.

Shin, E.J., Shin, H.M., Nam, E., Kim, W.S., Kim, J.H., Oh, B.H., and Yun, Y. (2012). DeSUMOylating isopeptidase: a second class of SUMO protease. EMBO Rep. 13, 339-346. https://doi.org/10.1038/embor.2012.3.

Shirayama, M., Tóth, A., Gálová, M., and Nasmyth, K. (1999). APC(Cdc20) promotes exit from mitosis by destroying the anaphase inhibitor Pds1 and cyclin Clb5. Nature 402, 203-207. https://doi.org/10.1038/46080.

Skaar, J.R., Pagan, J.K., and Pagano, M. (2013). Mechanisms and function of substrate recruitment by F-box proteins. Nat. Rev. Mol. Cell Biol. 14, 369-381. https://doi. org/10.1038/nrm3582.

Skaar,J.R., Pagan,J.K., and Pagano, M. (2014). SCF ubiquitin ligase-targeted therapies. Nat. Rev. Drug Discov. 13, 889-903. https://doi.org/10.1038/nrd4432.

Skoneczna, A., McIntyre, J., Skoneczny, M., Policinska, Z., and Sledziewska-Gojska, E. (2007). Polymerase eta is a short-lived, proteasomally degraded protein that is temporarily stabilized following UV irradiation in Saccharomyces cerevisiae. J. Mol. Biol. 366, 1074-1086.

Sommers, J.A., Suhasini, A.N., and Brosh, R.M. (2015). Protein degradation pathways regulate the functions of helicases in the DNA damage response and maintenance of genomic stability. Biomolecules 5, 590-616. https:// doi.org/10.3390/biom5020590.

Sonneville, R., Moreno, S.P., Knebel, A., Johnson, C., Hastie, C.J., Gartner, A., Gambus, A., and Labib, K. (2017). CUL-2(LRR-1) and UBXN-3 drive replisome disassembly during DNA replication termination and mitosis. Nat. Cell Biol. 19, 468-479.

Soucy, T.A., Smith, P.G., Milhollen, M.A., Berger, A.J., Gavin, J.M., Adhikari, S., Brownell, J.E., Burke, K.E., 
Cardin, D.P., Critchley, S., et al. (2009). An inhibitor of NEDD8-activating enzyme as a new approach to treat cancer. Nature 458, 732-736. https://doi.org/10.1038/ nature 07884 .

Sullivan, M., and Morgan, D.O. (2007). Finishing mitosis, one step at a time. Nat. Rev. Mol. Cell Biol. 8, 894-903.

Tada, S. (2007). Cdt1 and geminin: role during cell cycle progression and DNA damage in higher eukaryotes. Front. Biosci. 12, 1629-1641.

Tada, S., Li, A., Maiorano, D., Méchali, M., and Blow, J.J. (2001). Repression of origin assembly in metaphase depends on inhibition of RLF-B/Cdt1 by geminin. Nat. Cell Biol. 3, 107-113. https://doi. org/10.1038/35055000.

Takeda, D.Y., Parvin, J.D., and Dutta, A. (2005). Degradation of Cdt1 during $S$ phase is Skp2-independent and is required for efficient progression of mammalian cells through S phase. J. Biol. Chem. 280, 23416-23423.

Talbert, P.B., and Henikoff, S. (2017). Histone variants on the move: substrates for chromatin dynamics. Nat. Rev. Mol. Cell Biol. 18, 115-126. https://doi.org/10.1038/ nrm.2016.148.

Tammsalu, T., Matic, I., Jaffray, E.G., Ibrahim, A.F.M., Tatham, M.H., and Hay, R.T. (2014). Proteome-wide identification of SUMO2 modification sites. Sci. Signal. 7, rs2. https://doi.org/10.1126/scisignal.2005146.

Tanaka, S., and Diffley, J.F. (2002). Interdependent nuclear accumulation of budding yeast $\mathrm{Cdt} 1$ and $\mathrm{Mcm} 2-7$ during G1 phase. Nat. Cell Biol. 4, 198-207. https:// doi.org/10.1038/ncb757.

Tanaka, T., Knapp, D., and Nasmyth, K. (1997). Loading of an $\mathrm{Mcm}$ protein onto DNA replication origins is regulated by Cdc6p and CDKs. Cell 90, 649-660.

Tardat, M., Brustel, J., Kirsh, O., Lefevbre, C., Callanan, M., Sardet, C., and Julien, E. (2010). The histone H4 Lys 20 methyltransferase PR-Set7 regulates replication origins in mammalian cells. Nat. Cell Biol. 12, 1086-1093. https://doi.org/10.1038/ncb2113.

Tatsumi, Y., Ohta, S., Kimura, H., Tsurimoto, T., and Obuse, C. (2003). The ORC1 cycle in human cells: I. cell cycleregulated oscillation of human ORC1. J. Biol. Chem. 278, 41528-41534. https://doi.org/10.1074/jbc. M307534200.

Tatsumi, Y., Sugimoto, N., Yugawa, T., Narisawa-Saito, M., Kiyono, T., and Fujita, M. (2006). Deregulation of Cdt1 induces chromosomal damage without rereplication and leads to chromosomal instability. J. Cell Sci. 119, $3128-3140$

Teixeira, L.K., and Reed, S.I. (2013). Ubiquitin ligases and cell cycle control. Annu. Rev. Biochem. 82, 387-414. https://doi.org/10.1146/annurevbiochem-060410-105307.

Terai, K., Abbas, T., Jazaeri, A.A., and Dutta, A. (2010). CRL4(Cdt2) E3 ubiquitin ligase monoubiquitinates PCNA to promote translesion DNA synthesis. Mol. Cell 37, 143-149. https://doi.org/10.1016/j. molcel.2009.12.018.

Terai, K., Shibata, E., Abbas, T., and Dutta, A. (2013). Degradation of p12 subunit by CRL4Cdt2 E3 ligase inhibits fork progression after DNA damage. J. Biol. Chem. 288, 30509-30514. https://doi.org/10.1074/ jbc.C113.505586.
Thu, Y.M., and Bielinsky, A.K. (2013). Enigmatic roles of $\mathrm{Mcm} 10$ in DNA replication. Trends Biochem. Sci. 38, 184-194. https://doi.org/10.1016/j.tibs.2012.12.003.

Tokunaga, F., Sakata, S., Saeki, Y., Satomi, Y., Kirisako, T., Kamei, K., Nakagawa, T., Kato, M., Murata, S., Yamaoka, S., et al. (2009). Involvement of linear polyubiquitylation of NEMO in NF-kappaB activation. Nat. Cell Biol. 11, 123-132. https://doi.org/10.1038/ncb1821.

Torres-Ramos, C.A., Prakash, S., and Prakash, L. (2002). Requirement of RAD5 and MMS2 for postreplication repair of UV-damaged DNA in Saccharomyces cerevisiae. Mol. Cell. Biol. 22, 2419-2426.

Tsuji, T., Ficarro, S.B., and Jiang, W. (2006). Essential role of phosphorylation of MCM2 by Cdc7/Dbf4 in the initiation of DNA replication in mammalian cells. Mol. Biol. Cell 17, 4459-4472.

Ulrich, H.D., and Takahashi, T. (2013). Readers of PCNA modifications. Chromosoma 122, 259-274. https:// doi.org/10.1007/s00412-013-0410-4.

Unk, I., Hajdú, I., Fátyol, K., Hurwitz, J., Yoon, J.H., Prakash, L., Prakash, S., and Haracska, L. (2008). Human HLTF functions as a ubiquitin ligase for proliferating cell nuclear antigen polyubiquitination. Proc. Natl. Acad. Sci. U.S.A. 105, 3768-3773. https://doi.org/10.1073/ pnas. 0800563105.

van Deursen, F., Sengupta, S., De Piccoli, G., Sanchez-Diaz, A., and Labib, K. (2012). Mcm10 associates with the loaded DNA helicase at replication origins and defines a novel step in its activation. EMBO J. 31, 2195-2206. https://doi.org/10.1038/emboj.2012.69.

van Leuken, R., Clijsters, L., and Wolthuis, R. (2008). To cell cycle, swing the APC/C. Biochim. Biophys. Acta 1786, 49-59. https://doi.org/10.1016/j.bbcan.2008.05.002.

Vashee, S., Cvetic, C., Lu, W., Simancek, P., Kelly, T.J., and Walter, J.C. (2003). Sequence-independent DNA binding and replication initiation by the human origin recognition complex. Genes Dev. 17, 1894-1908. https://doi.org/10.1101/gad.1084203.

Vaziri, C., Saxena, S., Jeon, Y., Lee, C., Murata, K., Machida, Y., Wagle, N., Hwang, D.S., and Dutta, A. (2003). A p53dependent checkpoint pathway prevents rereplication. Mol. Cell 11, 997-1008.

Villa-Hernández, S., and Bermejo, R. (2018). Cohesin dynamic association to chromatin and interfacing with replication forks in genome integrity maintenance. Curr. Genet. 64, 1005-1013. https://doi.org/10.1007/ s00294-018-0824-x.

Visintin, R., Prinz, S., and Amon, A. (1997). CDC20 and $\mathrm{CDH} 1$ : a family of substrate-specific activators of APCdependent proteolysis. Science 278, 460-463.

Wagner, S.A., Beli, P., Weinert, B.T., Nielsen, M.L., Cox, J., Mann, M., and Choudhary, C. (2011). A proteome-wide, quantitative survey of in vivo ubiquitylation sites reveals widespread regulatory roles. Mol. Cell Proteomics 10, M111.013284. https://doi.org/10.1074/mcp. M111.013284.

Wallace, H.A., Merkle, J.A., Yu, M.C., Berg, T.G., Lee, E., Bosco, G., and Lee, L.A. (2014). TRIP/NOPO E3 ubiquitin ligase promotes ubiquitylation of DNA polymerase $\eta$. Development $141,1332-1341$. https:// doi.org/10.1242/dev.101196.

Walter, D., Hoffmann, S., Komseli, E.S., Rappsilber, J., Gorgoulis, V., and Sørensen, C.S. (2016). SCF(Cyclin 
F)-dependent degradation of CDC6 suppresses DNA re-replication. Nat. Commun. 7, 10530. https://doi. org/10.1038/ncomms10530.

Wang, C., Deng, L., Hong, M., Akkaraju, G.R., Inoue, J., and Chen, Z.J. (2001). TAK1 is a ubiquitin-dependent kinase of MKK and IKK. Nature 412, 346-351. https: / / doi.org/10.1038/35085597.

Wang, Z., Liu, P., Inuzuka, H., and Wei, W. (2014). Roles of F-box proteins in cancer. Nat. Rev. Cancer 14, 233-247. https://doi.org/10.1038/nrc3700.

Watanabe, N., Arai, H., Nishihara, Y., Taniguchi, M., Watanabe, N., Hunter, T., and Osada, H. (2004). M-phase kinases induce phospho-dependent ubiquitination of somatic Wee1 by SCFbeta-TrCP. Proc. Natl. Acad. Sci. U.S.A. 101, 4419-4424. https://doi.org/10.1073/ pnas. 0307700101 .

Waters, L.S., and Walker, G.C. (2006). The critical mutagenic translesion DNA polymerase Rev1 is highly expressed during G(2)/M phase rather than $S$ phase. Proc. Natl. Acad. Sci. U.S.A. 103, 8971-8976.

Waters, L.S., Minesinger, B.K., Wiltrout, M.E., D’Souza, S., Woodruff, R.V., and Walker, G.C. (2009). Eukaryotic translesion polymerases and their roles and regulation in DNA damage tolerance. Microbiol. Mol. Biol. Rev. 73, 134-154. https://doi.org/10.1128/MMBR.00034-08.

Wei, L., and Zhao, X. (2016). A new MCM modification cycle regulates DNA replication initiation. Nat. Struct. Mol. Biol. 23, 209-216. https://doi.org/10.1038/ nsmb.3173.

Wei, W., Ayad, N.G., Wan, Y., Zhang, G.J., Kirschner, M.W., and Kaelin, W.G. (2004). Degradation of the SCF component Skp2 in cell-cycle phase G1 by the anaphasepromoting complex. Nature 428, 194-198. https://doi. org/10.1038/nature02381.

Welcker, M., and Clurman, B.E. (2008). FBW7 ubiquitin ligase: a tumour suppressor at the crossroads of cell division, growth and differentiation. Nat. Rev. Cancer 8 , 83-93.

Wilkinson, K.D. (1997). Regulation of ubiquitin-dependent processes by deubiquitinating enzymes. FASEB J. 11, 1245-1256.

Wohlschlegel, J.A., Dwyer, B.T., Dhar, S.K., Cvetic, C., Walter, J.C., and Dutta, A. (2000). Inhibition of eukaryotic DNA replication by geminin binding to Cdt1. Science 290, 2309-2312. https://doi.org/10.1126/ science.290.5500.2309.

Wong, J.V., Dong, P., Nevins, J.R., Mathey-Prevot, B., and You, L. (2011). Network calisthenics: control of E2F dynamics in cell cycle entry. Cell Cycle 10, 3086-3094.

Wotton, D., and Shore, D. (1997). A novel Raplp-interacting factor, Rif2p, cooperates with Riflp to regulate telomere length in Saccharomyces cerevisiae. Genes Dev. 11, 748-760.

Wu, S., Wang, W., Kong, X., Congdon, L.M., Yokomori, K., Kirschner, M.W., and Rice, J.C. (2010). Dynamic regulation of the PR-Set7 histone methyltransferase is required for normal cell cycle progression. Genes Dev. 24, 2531-2542. https://doi.org/10.1101/gad.1984210.

Xiao, B., Jing, C., Kelly, G., Walker, P.A., Muskett, F.W., Frenkiel, T.A., Martin, S.R., Sarma, K., Reinberg, D., Gamblin, S.J., et al. (2005). Specificity and mechanism of the histone methyltransferase Pr-Set7. Genes Dev. 19, 1444-1454.
Xue, X., Choi, K., Bonner, J., Chiba, T., Kwon, Y., Xu, Y., Sanchez, H., Wyman, C., Niu, H., Zhao, X., et al. (2014). Restriction of replication fork regression activities by a conserved SMC complex. Mol. Cell 56, 436-445. https://doi.org/10.1016/j.molcel.2014.09.013.

Yamazaki, S., Ishii, A., Kanoh, Y., Oda, M., Nishito, Y., and Masai, H. (2012). Rif1 regulates the replication timing domains on the human genome. EMBO J. 31, 3667-3677. https://doi.org/10.1038/emboj.2012.180.

Yang, K., Weinacht, C.P., and Zhuang, Z. (2013). Regulatory role of ubiquitin in eukaryotic DNA translesion synthesis. Biochemistry 52, 3217-3228. https://doi. org/10.1021/bi400194r.

Yang, W.L., Zhang, X., and Lin, H.K. (2010). Emerging role of Lys-63 ubiquitination in protein kinase and phosphatase activation and cancer development. Oncogene 29, 4493-4503. https://doi.org/10.1038/ onc.2010.190.

Yin, Y., Yu, V.C., Zhu, G., and Chang, D.C. (2008). SET8 plays a role in controlling G1/S transition by blocking lysine acetylation in histone through binding to $\mathrm{H} 4$ N-terminal tail. Cell Cycle 7, 1423-1432.

Zachariae, W., and Nasmyth, K. (1999). Whose end is destruction: cell division and the anaphase-promoting complex. Genes Dev. 13, 2039-2058.

Zeman, M.K., Lin, J.R., Freire, R., and Cimprich, K.A. (2014). DNA damage-specific deubiquitination regulates Rad18 functions to suppress mutagenesis. J. Cell Biol. 206, 183-197. https://doi.org/10.1083/ jcb.201311063.

Zhang, S., Chea, J., Meng, X., Zhou, Y., Lee, E.Y., and Lee, M.Y. (2008). PCNA is ubiquitinated by RNF8. Cell Cycle 7, 3399-3404.

Zheng, N., and Shabek, N. (2017). Ubiquitin ligases: structure, function, and regulation. Annu. Rev. Biochem. 86, 129-157. https://doi.org/10.1146/annurevbiochem-060815-014922.

Zhong, W., Feng, H., Santiago, F.E., and Kipreos, E.T. (2003). CUL-4 ubiquitin ligase maintains genome stability by restraining DNA-replication licensing. Nature 423, 885-889. https://doi.org/10.1038/nature01747.

Zhu, W., and Depamphilis, M.L. (2009). Selective killing of cancer cells by suppression of geminin activity. Cancer Res. 69, 4870-4877. https://doi.org/10.1158/00085472.CAN-08-4559.

Zhu, W., and Dutta, A. (2006). An ATR- and BRCA1mediated Fanconi anemia pathway is required for activating the G2/M checkpoint and DNA damage repair upon rereplication. Mol. Cell. Biol. 26, 46014611.

Zhu, W., Chen, Y., and Dutta, A. (2004). Rereplication by depletion of geminin is seen regardless of p 53 status and activates a G2/M checkpoint. Mol. Cell. Biol. 24, 71407150. https://doi.org/10.1128/MCB.24.16.71407150.2004

Zhu, W., Ukomadu, C., Jha, S., Senga, T., Dhar, S.K., Wohlschlegel, J.A., Nutt, L.K., Kornbluth, S., and Dutta, A. (2007). Mcm10 and And-1/CTF4 recruit DNA polymerase alpha to chromatin for initiation of DNA replication. Genes Dev. 21, 2288-2299.

Zilio, N., Eifler-Olivi, K., and Ulrich, H.D. (2017). Functions of SUMO in the maintenance of genome 
Abbas

stability. Adv. Exp. Med. Biol. 963, 51-87. https://doi. org/10.1007/978-3-319-50044-7_4.

Zlatanou, A., Sabbioneda, S., Miller, E.S., Greenwalt, A., Aggathanggelou, A., Maurice, M.M., Lehmann, A.R.,
Stankovic, T., Reverdy, C., Colland, F., et al. (2016). USP7 is essential for maintaining Rad18 stability and DNA damage tolerance. Oncogene 35, 965-976. https://doi.org/10.1038/onc.2015.149 